NBER WORKING PAPER SERIES

\title{
DO MERGERS LEAD TO MONOPOLY IN THE LONG RUN? RESULTS FROM THE DOMINANT FIRM MODEL
}

\author{
Gautam Gowrisankaran \\ Thomas J. Holmes \\ Working Paper 9151 \\ http://www.nber.org/papers/w9151 \\ NATIONAL BUREAU OF ECONOMIC RESEARCH \\ 1050 Massachusetts Avenue \\ Cambridge, MA 02138 \\ September 2002
}

We thank Mark Armstrong, Andy Atkeson, Joe Harrington, Narayana Kocherlakota, Kai-Uwe Kuhn, Jim Levinsohn, Matt Mitchell, Volker Nocke, Ariel Pakes, Leo Simon, two anonymous referees, and seminar participants at the Federal Reserve Bank of Minneapolis, Georgetown, Michigan, Northwestern, Stanford, WesternOntario, the Stony Brook Game Theory Festival, and the Institute for Industrial Economics (IUI) Workshop on Mergers for helpful comments. We acknowledge editorial assistance from Anita Todd and research assistance from Jackie Yuen. Holmes acknowledges financial support from the National Science Foundation through Grant SES-9906087. The views expressed herein are solely those of the authors and do not represent the views of the National Bureau of Economic Research, or the Federal Reserve Banks of Minneapolis or San Francisco or the Federal Reserve System.

(C) 2002 by Gautam Gowrisankaran and Thomas J. Holmes. All rights reserved. Short sections of text, not to exceed two paragraphs, may be quoted without explicit permission provided that full credit, including (C) notice, is given to the source. 
Do Mergers Lead to Monopoly in the Long Run? Results from

the Dominant Firm Model

Gautam Gowrisankaran and Thomas J. Holmes

NBER Working Paper No. 9151

September 2002

JEL No. L1, L4

\begin{abstract}
Will an industry with no antitrust policy converge to monopoly, competition, or somewhere in between? We analyze this question using a dynamic dominant firm model with rational agents, endogenous mergers, and constant returns to scale production. We find that perfect competition and monopoly are always steady states of this model, and that there may be other steady states with a dominant firm and a fringe co-existing. Mergers are likely only when supply is inelastic or demand is elastic, suggesting that the ability of a dominant firm to raise price, through monopolization is limited. Additionally, as the discount factor increases, it becomes harder to monopolize the industry, because the dominant firm cannot commit to not raising prices in the future.
\end{abstract}

Gautam Gowrisankaran

Department of Economics

Harvard University

Littauer Center

Cambridge, MA 02138

and NBER

gautam_gowrisankaran@nber.org

Thomas J. Holmes

Department of Economics

University of Minnesota

1035 Heller Hall

271 - 19th Avenue South

Minneapolis, MN 55455

homes@econ.umn.edu 


\section{Introduction}

If there were no antitrust policy limiting mergers, would an industry with constant returns to scale tend toward monopoly in the long run? This is a basic question in industrial organization. Three key forces bear on this issue. First, a monopoly maximizes industry profits, which provides an incentive to consolidate industry capital. Second, as pointed out by Stigler (1950), there is a free-rider problem in the merger process that limits consolidation. Small firms may have an incentive to stay out of a consolidated enterprise so they can freeride on the attempts of large firms to raise prices. ${ }^{1} \quad$ Third, large firms have a different incentive to invest in industry capital than do small firms, because large firms internalize the effect that their investment has on industry output and prices. ${ }^{2} \quad$ Because of these opposing forces, when mergers are feasible long-run industry concentration is unknown. The purpose of this paper is to sort out the net effects of these three forces, in order to better understand the natural evolution of industry concentration.

In order to minimize the number of assumptions, we attempt to answer this question using the simplest possible model that incorporates all three key forces. We develop a dynamic rational expectations model with an endogenous merger process, and consider Markov-Perfect Equilibria for simplicity. Our model is based on the Kydland (1979) dynamic dominant firm model of an industry faced with a repeated demand curve for a homogeneous product. ${ }^{3}$ The industry is composed of one "large" dominant firm and a continuum of infinitesimally small firms that form a competitive fringe. In every period, there are two stages: a merger stage and an output/investment stage. In the first stage, the dominant firm chooses to acquire capital from the fringe by setting a price at which it will buy or sell as much capital as is supplied. ${ }^{4}$ In the second stage, the dominant firm chooses a market price. Competitive

\footnotetext{
1 The game theoretic implications of this insight are analyzed by Salant, Switzer, and Reynolds (1983), Perry and Porter (1985), d'Aspremont et al. (1983) and the literature that follows.

2 Because increased investment lowers prices, the immediate effect is that the dominant firm invests less than fringe firms. Stigler (1968, p. 108) described this as an "inverted umbrella" held by the dominant firm, that protects and encourages the growth of fringe firms. However, investment by the dominant firm also has the strategic effect of deterring investment by the fringe (see Spence (1977) and Dixit (1980)) which will counteract the immediate effect.

3 See Holmes (1996) for a recent use of this model. Alternative variants of the dominant firm model include Gaskins (1971) and Judd and Petersen (1986).

4 Our formulation of the merger process is similar to Shleifer and Vishny (1986), who look at the analogous problem of a large shareholder buying shares from a competitive fringe of shareholders.
} 
fringe firms then pick their production levels given the market price, with the dominant firm supplying the residual demand.

We make four assumptions about the technology. First, we assume that the dominant firm and the fringe share an identical constant returns to scale technology, which implies that mergers do not change the production possibility set. If the dominant firm were more efficient than the fringe or if there were increasing returns to scale, the dominant firm would obviously tend to gain share at the expense of the fringe. We are interested in understanding the evolution of concentration abstracting from these two well-understood factors. Second, we assume that capital used in the production process is specific to the industry. If capital were not industry-specific, then capital could flow instantaneously into the industry from other industries and issues of monopoly and dynamics would be moot. Third, we assume that there are increasing adjustment costs for expanding industry capital. There is a long tradition in economics for studying this kind of environment (see Lucas (1967)). Our conception of industry capital includes organization capital and relationship capital with customers. ${ }^{5}$

Lastly, we assume that new capital and output are linked in fixed proportions, which simplifies the analysis by allowing for only one decision per firm at the output/investment stage. We make this assumption for convenience and show that our results are robust to relaxing this assumption.

Our paper contributes to a recent literature that has attempted to endogenize the merger process, including Cheong and Judd (1992), Gowrisankaran (1999), Kamien and Zang (1990) and Nocke (2000). Because these papers have examined oligopoly models, they have had to deal with the complexity of modeling a merger process with many strategic actors. In contrast, by focusing on the dominant firm model, our analysis is vastly simplified, as we need only model the strategic actions of one agent. Two advantages stem from our simplification: First, our model is much more analytically tractable than earlier works such as Gowrisankaran (1999), and hence we can obtain analytic, and more easily interpretable, results. Second, we did not have to make many assumptions about the merger process, in contrast to an oligopoly model where there are many sensible potential processes. In spite of the simplifications, our model is able to capture the three key forces above.

5 Prescott and Visscher (1980) provide microfoundations for increasing adjustment costs in such environments. 
Using our model, we obtain two immediate results: pure monopoly will remain a monopoly forever, and a competitive industry will remain competitive forever. The reason for the monopoly result is that the industry profit force dominates: a monopoly maximizes total industry value and hence cannot gain from a sell-off. The reason for the competition result is that the free-rider force dominates: for a given market structure, a fringe firm maximizes the value per unit of capital, while the dominant firm earns less per unit of capital. In order to acquire capital, a dominant firm must pay the fringe its outside option, which is the value of being a fringe firm given the final industry structure. It follows that to acquire capital, an infinitesimally small dominant firm must pay the fringe a higher price than it can earn on each of its new units of capital, and, unlike a larger dominant firm, it does not have an existing base of capital that would benefit from the acquisition.

If the industry starts out in between a monopoly and perfect competition, there are several possibilities for the evolution of the industry. One possibility is that the industry converges to competition. Another possibility is that the industry converges to monopoly. Lastly, there are steady states where the dominant firm buys some fringe capital every period, but then invests less than the fringe to get back to the same original market share at the start of the next period.

We find that industry evolution in between the limits depends on three fundamental model parameters: the elasticities of fringe supply and industry demand and the discount factor. As fringe supply becomes more elastic, long-run concentration decreases. This result occurs because an increase in the elasticity of supply is equivalent to a decrease in the importance of industry-specific capital, and without industry-specific capital, mergers are futile. In contrast, as demand becomes more inelastic, long-run concentration decreases. This may seem counterintuitive since monopolization raises industry profits the most for inelastic demand. However, inelastic demand causes an even larger free-rider effect, because the dominant firm reacts to decreases in demand elasticity by reducing output, which causes higher prices and, in turn, causes the fringe firms to raise output, leading to an increased wedge between the dominant firm and fringe values. The increased wedge leads to less acquisition of capital by the dominant firm and less investment relative to the fringe, both of which lower the long-run concentration of the industry. 
High discount factors also lead to less concentration. In a one-period model, equivalently a model with fully myopic firms $(\beta=0)$, a dominant firm with a market share between 0 and 1 will always acquire a strictly positive amount of capital. The reason for this is that the dominant firm can fully commit to its behavior through its choice of a price. Thus, for small capital purchases, the dominant firm can break even by keeping prices the same, and enjoy a first-order gain by raising prices. ${ }^{6} \quad$ Even with $\beta=0$, the dominant firm will not necessarily merge to monopoly immediately because of its monopsony power on the capital market. $^{7} \quad$ As $\beta$ increases, future prices become more and more important, lessening the commitment inherent in setting the current price. ${ }^{8}$ The result is that the dominant firm sells off some capital provided its initial share is low and $\beta$ is large, and, more generally, that the evolution of industry concentration is decreasing in $\beta$.

The remainder of this paper is divided as follows. Section 2 presents the model. Section 3 presents results for a single-period variant of the model. Section 4 presents results for the general model with multiple periods and forward-looking agents. Section 5 provides robustness checks of the assumption that capital and output are produced in fixed proportions. Section 6 concludes.

\section{The Model}

We adopt a discrete time model of a dynamic, infinitely lived industry. In the model, firms choose actions to maximize their expected discounted value of profits. In each period there is a merger process followed by an output/investment process. We model the industry in partial equilibrium with a demand curve that is constant over time. We start by detailing the preferences and technologies and then define the equilibrium of the model.

\subsection{Preferences and Technologies}

Demand at price $p$ is $Q=D(p)$. Assume demand is strictly decreasing, and let $p=D^{-1}(Q) \equiv$ $P(Q)$ denote the inverse demand curve. The discount factor is $\beta$.

$\overline{6}$ This argument goes back to Gilbert and Newbery (1982) and the literature of the persistence of monopoly.

7 The argument here is analogous to the Lewis (1983) result that an incumbent firm faced with a decision to simultaneously purchase multiple lumps of capital will purchase some but not necessarily all of them.

8 This result is analogous to Krishna (1993) who shows that the Gilbert and Newbery (1982) result does not necessarily hold when multiple units of a good are to be sold sequentially. 
We explain the technologies of the output/investment process (the second stage) and the merger process (the first stage). At the start of the output/investment process, there is a dominant firm and a competitive fringe, endowed with $K_{d}$ and $K_{f}$ units of capital stock, respectively. The capital stock is specific to the industry. The fringe is composed of a continuum of firms, each of which owns an infinitesimally small amount of $K_{f}$ and hence is a price taker.

The dominant firm and the fringe firms all have access to the same technology, and they produce homogeneous products. Firms combine industry-specific capital $K$ with nonindustry-specific labor $L$ in a production process $F(K, L)$ that produces joint outputs, the consumption good $Q$ and future capital $K_{\text {next }}$. The two outputs are produced in fixed proportions. Let $Q=F(K, L)$ be the production of the consumption good and $K_{\text {next }}=$ $\sigma F(K, L)$ be the production of future capital given inputs $K$ and $L$, where $0<\sigma<1$. We assume that current capital $K$ is consumed in the production process. If we interpret $Q$ as a measure of end-of-period capital and define $\delta \equiv 1-\sigma$, then $\delta$ can be interpreted as the depreciation rate, since $K_{n e x t}=(1-\delta) Q$, and $\sigma$ as the fraction of end-of-period capital that survives into the next period.

We make several assumptions about $F(K, L)$. First, we assume constant returns to scale. Thus, the size of the dominant firm confers no advantage or disadvantage in the production process relative to the fringe. Second, we assume that $F(0, L)=0$. It is therefore impossible to produce in this industry without any industry-specific capital. If the dominant firm somehow were to obtain all the industry-specific capital, monopoly could be ensured forever. Third, we assume that $F(K, L)$ is strictly concave and is strictly increasing in both arguments (for $K>0$ and $L>0$ ) and that the Inada conditions on $L, \lim _{L \rightarrow \infty} F_{L}(K, L)=0$ and $\lim _{L \rightarrow 0} F_{L}(K, L)=\infty$, hold for $K>0$.

In the analysis it will be convenient to utilize a labor cost function rather than the underlying production function. Let $C(Q, K)$ be the labor cost to produce $Q$ units of the consumption good (and $\sigma Q$ of next-period capital); i.e., $C(Q, K)=\omega L^{\prime}$ for the $L^{\prime}$ that solves $Q=F\left(K, L^{\prime}\right)$, given the competitive wage $\omega$. The assumptions on $F(K, L)$ imply that $C(Q, K)$ is homogenous of degree 1 , so that $C(Q, K)=K C(Q / K, 1)$. In the analysis we use lower case $q$ to denote output per unit of capital; i.e., $q=Q / K$. Let $c(q)=C(q, 1)$ 
denote the labor cost per unit of capital necessary to produce $q$ units of output per unit of capital. The assumptions on $F$ imply that $c$ is strictly increasing and strictly convex and that $c^{\prime}(0)=0$. As a result, our model fits into the class of standard increasing adjustment cost models of capital.

The timing in the output/investment stage follows the textbook treatment of the dominant firm model (see Carlton and Perloff (1994)). The dominant firm first sets an industry price. The fringe firms observe this price and simultaneously decide on production levels. The dominant firm supplies the residual demand at the price. Equivalent to our assumption that the dominant firm chooses the price from a residual demand curve, we could assume that it chooses the quantity from the same residual demand curve. We will work with this alternate quantity formulation in the following sections as it is notationally more convenient; Perry and Porter (1985) do the same.

We now turn to the merger process, which precedes the output/investment process every period. In this process, the dominant firm posts a price at which it commits to buy or sell all the capital that is supplied or demanded at this price. The fringe firms then simultaneously choose whether or not to sell to the dominant firm given the price and their expectation of the future state. This amount of capital purchased can be zero (corresponding to no merger) or negative (corresponding to a divestiture). It is again more convenient to work with the alternate but equivalent formulation where the dominant firm chooses a quantity of capital to purchase and then picks the price that would yield this quantity.

It should be pointed out that the single-period version of our model is similar to the model of Perry and Porter (1985) with one exception. They assume the fringe will merge with the dominant firm if the total return to the merged entity exceeds what the firms would get separately. An extensive form that would generate this is that the dominant firm makes take-it-or-leave-it offers to all firms in the fringe sector; if any one fringe firm declines to tender its capital at the offered price, the deal falls through for all the fringe firms and no merger takes place. In contrast, we assume, as do Shleifer and Vishny (1986), that every individual fringe firm is an infinitesimally small player. If one fringe firm chooses not to tender its capital at the posted price, it has no effect on the rest of the market. With our assumption, there is a much stronger free-rider effect against merger as compared to 
Perry and Porter (1985), since a dominant firm must pay the fringe its reservation value at the resulting more-concentrated industry structure and not at the original one. ${ }^{9}$ An appealing property of our assumption is that it extends the standard assumption that fringe firms behave competitively in the output market: in our framework, fringe firms behave competitively in the capital market as well as the output market and the dominant firm behaves strategically in both markets.

\subsection{Equilibrium of the Model}

We analyze the Markov-Perfect Equilibria (MPE) of our model in the sense of Maskin and Tirole (1988). This means that we examine equilibria where actions are a function solely of payoff relevant state variables, which are the capital stocks in our case. Let $\left(K_{d}^{\circ}, K_{f}^{\circ}\right)$ denote the capital stocks held by the dominant firm and fringe before the merger stage has taken place. Let $\left(K_{d}, K_{f}\right)$ denote the capital stocks after the merger stage but before the output/investment stage. (Throughout, the superscript "o" will denote pre-merger values, and the absence of a superscript will signify post-merger values.) The total capital stock $K$ is the same before and after the merger stage, $K=K_{d}+K_{f}=K_{d}^{\circ}+K_{f}^{\circ}$. It will be convenient to keep track of the state with the total capital stock and the share of the total held by the dominant firm. Let $m^{\circ}=K_{d}^{\circ} / K$ be the industry concentration before the merger stage, and let $m=K_{d} / K$ denote the concentration after the merger stage.

Define $v_{f}(m, K)$ to be the discounted value to a fringe firm possessing one unit of capital at the output/investment stage when the aggregate state is $(m, K)$. Analogously, define $v_{d}(m, K)$ to be the discounted value to the dominant firm per unit of capital possessed by the dominant firm. Since the dominant firm holds $m K$ units of capital at this stage, its total return is $w_{d}(m, K)=m K v_{d}(m, K)$. Throughout the paper, a " $v$ " will denote a return per unit of capital, while a " $w$ " denotes a total return.

The merger stage begins with the dominant firm holding a share $m^{\circ}$ of the total industry capital. Let $w_{d}^{\circ}\left(m^{\circ}, K\right)$ be the maximized total return to the dominant firm at this stage. The dominant firm posts a price of capital $p_{K}$ at which it commits to purchase the net amount of capital supplied by the fringe at this price (which may be negative). By varying

9 Indeed, it is straightforward to see that immediate merger to monopoly will always result if we use a take-it-or-leave-it merger process with our model. 
the price $p_{K}$, the dominant firm affects the amount of capital supplied, and thus it picks a point on the supply curve of capital. In writing down the dominant firm's problem, it is convenient to have the firm's choice variable be quantity rather than price. In particular, we let the post-merger share $m$ be the choice variable of the dominant firm. Given $m$, the amount of capital purchased by the dominant firm is $m K-m^{\circ} K$, total post-merger capital less total pre-merger capital. Given the post-merger share $m$, the equilibrium price of capital is

$$
p_{K}(m, K)=v_{f}(m, K)
$$

This is the price at which fringe firms are indifferent among buying, selling, or holding onto their capital. Thus the dominant firm makes its merger choice $m$ to solve

$$
\begin{aligned}
w_{d}^{\circ}\left(m^{\circ}, K\right) & =\max _{m} m K v_{d}(m, K)-\left(m K-m^{\circ} K\right) p_{K}(m, K) \\
& =\max _{m} m K v_{d}(m, K)-\left(m-m^{\circ}\right) K v_{f}(m, K) .
\end{aligned}
$$

The first term in the objective function is the dominant firm's return entering the output/investment stage with a share of $m$ and thus $m K$ total units of capital. The second term subtracts the amount spent on the acquisition of capital (this subtracts a negative number in the event of a sell-off). Let $\tilde{m}\left(m^{\circ}, K\right)$ be the solution to this problem.

Let $v_{f}^{\circ}\left(m^{\circ}, K\right)$ be the return per unit of capital to the fringe before the merger stage. Given the merger policy of the dominant firm, this satisfies

$$
v_{f}^{\circ}\left(m^{\circ}, K\right)=v_{f}\left(\tilde{m}\left(m^{\circ}, K\right), K\right)
$$

Now consider the output/investment stage. Let $q_{d}$ and $q_{f}$ denote output per unit of capital for each firm type, so total output in the dominant firm and fringe sectors is $Q_{d}=$ $m K q_{d}$ and $Q_{f}=(1-m) K q_{f}$. Recall that when fringe firms make their output/investment decision, the dominant firm has already made its move. Let $\tilde{q}_{f}\left(q_{d}, m, K\right)$ be the equilibrium output choice (per unit of capital) in the fringe sector, given the choice $q_{d}$ by the dominant 
firm and given $m$ and $K$. This solves the following problem:

$$
\begin{aligned}
& \tilde{q}_{f}\left(q_{d}, m, K\right)=\underset{q_{f}}{\arg \max } p q_{f}-c\left(q_{f}\right)+\beta v_{f, \text { next }}^{\circ}(1-\delta) q_{f} \\
& \text { where : } \\
& p=P(Q) \\
& Q=m K q_{d}+(1-m) K \tilde{q}_{f}\left(q_{d}, m, K\right) \\
& v_{f, \text { next }}^{\circ}=v_{f}^{\circ}\left(m_{\text {next }}^{\circ}, K_{\text {next }}\right) \\
& m_{\text {next }}^{\circ}=\frac{m K q_{d}}{m K q_{d}+(1-m) K \tilde{q}_{f}\left(q_{d}, m, K\right)} \\
& K_{\text {next }}=(1-\delta) Q \text {. }
\end{aligned}
$$

Because it is infinitesimally small, an individual fringe firm takes the current price $p$ and the future per-unit-of-capital value $v_{f, n e x t}^{\circ}$ as fixed when making its output/investment decision. A choice of $q_{f}$ yields current revenues of $p q_{f}$ and a current cost of $c\left(q_{f}\right)$. It also yields $(1-\delta) q_{f}$ units of capital next period, each unit of which will be worth $v_{f, n e x t}^{\circ}$. The representative fringe assumes that the other firms in the fringe sector will behave according to $\tilde{q}_{f}\left(q_{d}, m, K\right)$, so the total fringe sector output will be $Q_{f}=(1-m) K \tilde{q}_{f}\left(q_{d}, m, K\right)$. Given this anticipated fringe output and the observed dominant firm output, the representative fringe can calculate what the current price is and what the future capital stocks and prices will be. Note that the dominant firm's next-period pre-merger share $m_{\text {next }}^{\circ}$ is equal to the dominant firm's output share in the current period. This is a convenient feature of the assumption of a fixed-proportions technology for the current consumption good and future capital since the next period's total capital equals current output times $\sigma$.

The final step is to look at the dominant firm's output/investment decision given that the state is $(m, K)$ after the merger stage. It knows that the fringe sector behaves according to $\tilde{q}_{f}\left(q_{d}, m, K\right)$. As above, it is convenient and equivalent to have the firm's choice variable 
be quantity rather than price. It chooses $q_{d}$ to maximize value per unit of initial capital,

$$
\begin{aligned}
v_{d}(m, K) & =\max _{q_{d}} p\left(q_{d}\right) q_{d}-c\left(q_{d}\right)+\frac{\beta w^{\circ}\left(m_{\text {next }}^{\circ}\left(q_{d}\right), K_{\text {next }}\left(q_{d}\right)\right)}{m K} \\
\text { subject to } & : \\
p\left(q_{d}\right) & =P\left(Q\left(q_{d}\right)\right) \\
Q\left(q_{d}\right) & =m K q_{d}+(1-m) K \tilde{q}_{f}\left(q_{d}, m, K\right) \\
m_{\text {next }}^{\circ}\left(q_{d}\right) & =\frac{m K q_{d}}{m K q_{d}+(1-m) K \tilde{q}_{f}\left(q_{d}, m, K\right)} \\
K_{\text {next }}\left(q_{d}\right) & =(1-\delta) Q\left(q_{d}\right) .
\end{aligned}
$$

(Note this is equivalent to maximizing the dominant firm's total value since initial capital is fixed at $m K$.) Unlike a fringe firm, the dominant firm recognizes that its output/investment choice has an effect on the current and future prices. The dominant firm also factors in the effect of its choice of $q_{d}$ on the equilibrium fringe supply $\tilde{q}_{f}\left(q_{d}, m, K\right)$.

Having defined these various functions, we can define a MPE of this model. In particular, an MPE is a set of functions $\left(v_{f}^{\circ}, v_{f}, v_{d}, w_{d}^{\circ}, \tilde{q}_{f}, \tilde{q}_{d}, \tilde{m}\right)$ such that:

(i) The per-unit-of-capital value $v_{f}^{\circ}\left(m^{\circ}, K\right)$ solves (2).

(ii) The per-unit-of-capital $v_{f}(m, K)$ is the value of (3) for $q_{d}$ evaluated at $q_{d}=\tilde{q}_{d}(m, K)$.

(iii) The per-unit-of-capital value $v_{d}(m, K)$ solves (4).

(iv) The total value $w_{d}^{\circ}\left(m^{\circ}, K\right)$ solves (1).

(v) The policy function $\tilde{q}_{f}\left(q_{d}, m, K\right)$ solves (3).

(vi) The policy function $\tilde{q}_{d}(m, K)$ solves (4).

(vii) The policy function $\tilde{m}\left(m^{\circ}, K\right)$ solves (1).

\section{The Single-Period Model}

This section characterizes the single-period version of our model. We start with this case primarily because it is more analytically tractable but still captures the three key strategic effects noted. Thus, the single-period model allows us to understand the impact of these effects. In addition, our analysis of this version allows us to understand how the results with high $\beta$ differ from the results with low $\beta$ in the multi-period model, because in the limiting case where $\beta=0$, merger and investment behavior is the same as in the single-period model. 
It is notationally convenient in this section to normalize $K=1$, as it allows us to eliminate $K$ from the state space. When $K=1, m^{\circ}$ and $m$ are the dominant firm's pre-merger and post-merger capital levels as well as shares.

Our first result considers industry evolution starting at the extreme points of monopoly or competition, $m^{\circ}=1$ or $m^{\circ}=0$. Two general principles emerge here. If we begin the period with monopoly, we stay with monopoly. If we begin with perfect competition, we stay with perfect competition. Formally,

Proposition 1 The equilibrium merger policy function $\tilde{m}\left(m^{\circ}\right)$ satisfies $\tilde{m}(1)=1$ and $\tilde{m}(0)=$ 0 .

Proof. Applying (1) to the case of $m^{\circ}=1$, the dominant firm's problem is

$$
\max _{m}\left\{m v_{d}(m)+(1-m) v_{f}(m)\right\}
$$

The objective function here is the sum of the dominant firm profit plus the fringe sector profit, which equals total industry profit. Total industry profit is maximized with monopoly. It is apparent from the analysis below that for $m<1$ industry profit is less than the pure monopoly profit. Hence the unique solution is $m=1$.

For the case of $m^{\circ}=0$, applying (1) again, the dominant firm's problem is

$$
\max _{m}\left\{m v_{d}(m)-m v_{f}(m)\right\}
$$

At $m=0$, the value in (6) is 0 . From (3) and (4), a fringe firm could always choose the dominant firm quantity choice and earn $v_{d}(m)$. However, since $v_{f}(m)$ maximizes the fringe earnings, it must be at least as high as $v_{d}(m)$. Thus, for $m>0, v_{d}(m) \leq v_{f}(m)$. Hence $m=0$ is a solution to the dominant firm's merger choice. Below we show that $v_{d}(m)<v_{f}(m)$ for $m>0$, which implies that $m=0$ is the unique solution to the merger choice problem.

The monopoly result is due to the industry profits force in our model: a monopoly maximizes industry profits. If the dominant firm were to start at pure monopoly, its return would equal the entire industry profit. By divesting itself of capital and making the industry more competitive, it would reduce industry profit and hence its own return. The competition result is due to the free-rider force of our model: the dominant firm must pay the fringe its reservation price, but since a competitive firm maximizes profits conditional on a given 
industry structure, the dominant firm has to pay more for capital than it can earn from this capital. ${ }^{10}$

Our next results concern what happens between the extremes of $m^{\circ}=0$ and $m^{\circ}=1$. These results require an analysis of first-order conditions in the output/investment stage and the merger stage. With a single period, the first-order condition of the fringe firm's problem in the output/investment stage (3) reduces to

$$
p-c^{\prime}\left(q_{f}\right)=0
$$

i.e., price equals marginal cost. The first-order condition of the dominant firm's problem (4) can be written as

$$
M R_{d}-c^{\prime}\left(q_{d}\right)=0
$$

where the dominant firm's marginal revenue is

$$
M R_{d} \equiv p+q_{d} \frac{d P}{d Q}\left[m+(1-m) \frac{\partial q_{f}}{\partial q_{d}}\right] .
$$

To interpret (8), consider a decision by the dominant firm to expand its total output by one unit. It gets a price $p$ for the extra unit. But this action will depress the price on the $m q_{d}$ units that it is already selling. If the dominant firm were a monopoly, then the change in price would be $\frac{d P}{d Q}$, and the bracketed term in (8) would equal 1 . This is the direct part of the investment effect. Now suppose that there is a non-zero fringe. Then, any increase in dominant firm quantity is mitigated by a decrease in fringe quantity. This is the strategic (Spence (1977) and Dixit (1980)) part of the investment effect that has the opposite sign from the direct part. Thus, the bracketed term is less than 1 for a dominant firm with a fringe. However, it is straightforward to show that the direct part dominates and hence that the bracketed term must be strictly positive. ${ }^{11}$ In combination with the fact that $\frac{d P}{d Q}<0$, we have shown

$\overline{{ }^{10} \text { Although we do not model this explicitly, }}$ this result implies that there is no incentive for a second dominant firm to emerge out of the fringe.

11If the bracketed term were not strictly positive, then an increase in dominant firm quantity would not raise total industry output and hence not lower price. But, if price does not fall, then the fringe must not be contracting output. As the dominant firm is expanding output, total industry output is rising, which yields a contradiction. 
Lemma $1 A$ dominant firm with $m>0$ has $M R_{d}<p$, and hence $q_{d}<q_{f}$.

Proof. In the Appendix, we obtain an algebraic expression for $M R_{d}$, which implies the result.

The difference between a fringe firm and the dominant firm is that a fringe firm's sales are infinitesimally small, and so the second term in (8) drops out. In Figure 1, we illustrate the dominant firm and fringe output decisions. The dominant firm produces at the level $q_{d}$, where $M R_{d}$ equals marginal cost. The profit per unit of capital obtained by the dominant firm is illustrated by the lightly shaded area in the graph between the price line and the marginal cost curve up to $q_{d}$. A fringe firm could always choose to produce at $q_{d}$ and obtain the dominant firm profit. But it can do even better by raising its output to $q_{f}$, where the price equals marginal cost. The fringe value equals the light gray area (the dominant firm value) plus the dark gray triangle between $q_{d}$ and $q_{f}$. Thus $v_{d}(m)<v_{f}(m)$ for $m>0$. But note that at the extreme where $m=0$, the dominant firm behaves like a perfectly competitive firm, $q_{d}=q_{f}$, and the return per unit of capital is the same, $v_{d}(0)=v_{f}(0)$.

Even though the average value per unit of capital is higher for the fringe, it can be seen from Figure 1 that the marginal value of transferring a unit of capital from the fringe to the dominant firm is higher than the fringe value of this capital. This is the Gilbert and Newbery (1982) result. Formally,

\section{Lemma 2}

$$
\frac{d\left[m v_{d}(m)\right]}{d m}=v_{d}(m)+m \frac{d v_{d}(m)}{d m}>v_{f}(m), \text { for } m>0 .
$$

Proof. The reason for this result is that, to a first order, the dominant firm can break even by operating the new capital at the same rate as the fringe, and can gain by lowering the output level on the new capital from $q_{f}$ to $q_{d}$. We derive a formal algebraic proof in the Appendix and go through a graphical proof based on Figure 1 here.

Suppose that a unit of capital that is initially in the fringe sector is transferred to the dominant firm. The dominant firm could always choose to operate the capital unit at the level $q_{f}$, the same level the fringe firm would choose. Given that the quantity for the dominant firm's units remains unchanged, the remaining fringe would not change its quantity, and price would remain unchanged. Hence, in this case the dominant firm would earn $p q_{f}-c\left(q_{f}\right)$ 
on this new unit of capital, which is the fringe profit $v_{f}(m)$ (the light gray and dark gray areas in Figure 1). Thus, by setting the same quantity, the marginal value to the dominant firm of the new capital would be exactly $v_{f}(m)$.

Now suppose that the dominant firm were to increase the price by decreasing output on this newly transferred capital unit. For each unit decrease in output, dominant firm revenues fall by $M R_{d}$ and costs fall by marginal cost. But since marginal cost in this region is above $M R_{d}$ (by Lemma 1 ), the dominant firm's profit increases as $q$ is decreased. Reducing output from $q_{f}$ to $q_{d}$ raises the dominant firm's profit on the newly transferred unit by the black triangle in Figure 1. Thus, the black triangle is the amount by which the marginal benefit of the unit to the dominant firm exceeds the value of the unit to the fringe. This triangle is equal to the difference between the dominant firm's total value from operating the capital at the rate $q_{f}$ (which is $M R_{d} q_{f}-c\left(q_{f}\right)$ ) and at the rate $q_{d}$ (which is $M R_{d} q_{d}-c\left(q_{d}\right)$ ). Algebraically, we have shown

$$
\begin{aligned}
& \frac{d\left[m v_{d}(m)\right]}{d m} \\
= & {\left[p q_{f}-c\left(q_{f}\right)\right]+\int_{q_{d}}^{q_{f}}\left(c^{\prime}(q)-M R_{d}\right) d q } \\
= & v_{f}(m)+\int_{q_{d}}^{q_{f}}\left(c^{\prime}(q)-M R_{d}\right) d q \\
= & v_{f}(m)+\left(M R_{d} q_{d}-c\left(q_{d}\right)\right)-\left(M R_{d} q_{f}-c\left(q_{f}\right)\right) \\
> & v_{f}(m)
\end{aligned}
$$

for $m>0$.

We can use Lemma 2 to understand the dominant firm's incentive to merge. We start by differentiating the dominant firm's acquisition choice (1). Recall that the dominant firm's problem is

$$
\tilde{m}\left(m^{\circ}\right)=\underset{m}{\arg \max }\left\{m v_{d}(m)-\left(m-m^{\circ}\right) v_{f}(m)\right\} .
$$

Define the merger marginal benefit to be the slope of this objective function,

$$
\begin{aligned}
& \text { merger marginal benefit } \\
\equiv & v_{d}(m)+m \frac{d v_{d}(m)}{d m}-v_{f}(m)-\left(m-m^{\circ}\right) \frac{d v_{f}(m)}{d m} .
\end{aligned}
$$


If the dominant firm alters its acquisition decision to purchase one more unit of capital, it can earn a profit of $v_{d}$ on this new unit (the first term), and acquiring this extra unit drives up the profit on the units of capital the dominant firm is taking into the output/investment stage (the second term). But the dominant firm has to pay $v_{f}$ for it (the third term), and buying one extra unit raises the price of capital in the capital market (the fourth term).

From Lemma 2, we know that the net effect of the first three terms is strictly positive. The fourth term limits the incentive of the dominant firm to buy up all the capital because as it does so it raises the price of capital; the dominant firm recognizes its monopsony power in the capital market and factors this effect into its decision. (An analogous effect is in Lewis (1983).) But note that at $m=m^{\circ}$, this monopsony effect is zero since acquisitions are zero, so the fourth term of (10) is zero at this point. Thus a small positive merger is always better than a zero merger. In order to rule out the case of $m<m^{\circ}$, we impose the following intuitive regularity condition:

Assumption 1. The demand function $D(p)$ and the cost function $c(q)$ are such that the equilibrium price $\tilde{p}(m)$ is strictly increasing in $m$, for $m>0$.

We can show this assumption is satisfied under the constant elasticity parameterization for demand and cost given by (20) below. We then obtain

Proposition 2 Suppose that $\beta=0$, that $m^{\circ} \in(0,1)$, and that Assumption 1 holds. Then, the optimal capital purchase is strictly positive, $\tilde{m}\left(m^{\circ}\right)>m^{\circ}$. Moreover, $\tilde{m}\left(m^{\circ}\right)$ is increasing in $m^{\circ}$.

Proof. Using (10) and Lemma 2,

$$
\text { merger marginal benefit }>-\left(m-m^{\circ}\right) \frac{d v_{f}(m)}{d m} \text {. }
$$

Now, $\frac{d v_{f}}{d m}=q_{f} \frac{d p}{d m}$ by the envelope theorem. Thus, Assumption 1 implies that $v_{f}(m)$ is increasing in $m$. Using this fact, equation (11) shows that merger marginal benefit is strictly positive for $m \in\left[0, m^{\circ}\right]$. Thus, the optimal choice of $m$ is strictly greater than $m^{\circ}$. Next note that the slope of the merger marginal benefit with respect to $m^{\circ}$ equals $\frac{d v_{f}}{d m}$ which is strictly positive under Assumption 1. This immediately implies that the optimum $\tilde{m}\left(m^{\circ}\right)$ is monotonic.

While a positive merger is optimal, the dominant firm may not necessarily merge to complete monopoly because of its monopsony power in the capital market. The more capital 
it acquires, the higher the price it must pay per unit of capital. However, if the dominant firm initial share $m^{\circ}$ is close to 1 , the monopsony power effect is a second-order consideration and there is complete merger to monopoly, as long as the following assumption holds.

Assumption 2. The fringe value at pure monopoly is bounded, $v_{f}(1)<\infty$.

This assumption holds if and only if the pure monopoly price is bounded. We state the assumption in terms of the fringe value to make it comparable to the next section. If demand is constant elasticity, Assumption 2 is satisfied if and only if the demand elasticity is strictly greater than one. We then obtain

Proposition 3 Suppose Assumptions 1 and 2 both hold. Then, there exists a cutoff $\hat{m}^{\circ}$ satisfying $0<\hat{m}^{\circ}<1$ such that $\tilde{m}\left(m^{\circ}\right)=1$ if and only if $m^{\circ} \geq \hat{m}^{\circ}$. Thus for $m^{\circ}$ above the cutoff, the dominant firm buys the entire stock of fringe capital.

Proof. By Assumption 2, the monopoly price is finite. Thus, the first-order necessary condition (7) for the firm's output choice holds at $m=1$, and Lemma 2 can be applied to the $m=1$ case. From Lemma 2, the first three terms of merger marginal benefit are strictly positive at $m=1$. If $m^{\circ}=m=1$, the fourth term is zero, so merger marginal benefit is strictly positive. Using Proposition 2 and continuity, for $m^{\circ}$ close enough to 1 , the optimal merger must be the corner solution $\tilde{m}\left(m^{\circ}\right)=1$. From Proposition 1 , for $m^{\circ}$ close enough to $0, \tilde{m}\left(m^{\circ}\right)<1$. Since $\tilde{m}\left(m^{\circ}\right)$ is nondecreasing from Proposition 2 , there must be an interior cutoff $\hat{m}^{\circ}$ as claimed.

Our next result concerns what happens in the output/investment stage in the event that the initial share $m^{\circ}$ is less than the cutoff $\hat{m}^{\circ}$ where there is merger to monopoly. For this result, define $m_{\text {next }}^{\circ}(m)$ to be the dominant firm's share of new capital at the end of the period. (We use the subscript next because if there were an additional period added to this single-period model, $m_{\text {next }}^{\circ}(m)$ would be the pre-merger dominant firm share in the next period.) Given the fixed proportions assumption for new capital and output, the end-ofperiod new capital share equals the output share,

$$
m_{\text {next }}^{\circ}(m)=\frac{m q_{d}}{m q_{d}+(1-m) q_{f}}
$$

where $q_{d}$ and $q_{f}$ are the equilibrium levels of output and are implicitly a function of $m$. Our result is 
Proposition 4 Suppose that $m^{\circ} \in\left(0, \hat{m}^{\circ}\right)$, so that there is a positive merger $\tilde{m}\left(m^{\circ}\right)>m^{\circ}$ but no merger to monopoly, $\tilde{m}\left(m^{\circ}\right)<1$. Then, $m_{\text {next }}^{\circ}(m)$ is strictly less than the current post-merger share; i.e., $m_{\text {next }}^{\circ}\left(\tilde{m}\left(m^{\circ}\right)\right)<\tilde{m}\left(m^{\circ}\right)$.

Proof. From Lemma 1, we know that $q_{d}<q_{f}$; i.e., the dominant firm invests at a lower rate than the fringe. The result is an immediate consequence.

Note that if there were no merger stage, this investment force would be the only effect, and the dominant firm's market share would necessarily decline to zero in the long run (see Holmes (1996)). With mergers, there are two offsetting effects on concentration. The merger stage increases concentration, while the output/investment stage decreases concentration. The net effect is, in general, ambiguous.

\section{The Multi-Period Model}

We now turn to an analysis of the dynamics in the multi-period model. We start by examining industry dynamics at the extreme points of monopoly and competition. We then consider dynamics near the steady states of competition and monopoly. Lastly, we compute equilibria of the model to obtain numerical results away from the limits.

For our analysis in this section, it is convenient to consider the equilibrium for a version of our model with a finite horizon $T$ and then consider the limit as the number of periods $T$ goes to infinity. Following the results of Fudenberg and Levine (1986), if the sequence of equilibria defined for the finite horizon case has a limit, this limit is an equilibrium of the infinite horizon game. ${ }^{12}$ In our results here for the infinite horizon case, we restrict attention only to those equilibria that are limits of equilibria in the finite horizon case.

Additionally, it is useful for our analysis to define the equilibrium transition function for the evolution of market share from one period to the next as

$$
F\left(m^{\circ}, K\right)=m_{\text {next }}^{\circ}\left(\tilde{m}\left(m^{\circ}, K\right), K\right) .
$$

12Formally, our game has an infinite number of agents, and the Fudenberg and Levine (1986) result only applies to games with a finite number of agents. However, our game is equivalent to a game with three agents, a fringe, a dominant firm, and a market maker, where the dominant firm moves first followed by simultaneous moves by the fringe and market maker. For this variant, the dominant firm behavior and values are equivalent to our original game, the market maker sets $\tilde{q}_{f}$ and $\tilde{m}$ and gets its maximal payoff when conditions (v) and (vii) hold (i.e. the markets clear), and the fringe earns payoffs given that aggregate industry evolution is characterized by $\tilde{q}_{f}$ and $\tilde{m}$. It is straightforward to show that the set of equilibria are the same for the two games and hence that the games are equivalent. 
Note that (13) is a composite of two effects, the merger and output/investment effects.

\subsection{The Limits of Perfect Competition and Pure Monopoly}

At the limits of perfect competition and monopoly, the single-period and multi-period models will have the same dynamics, without any merger or sell-offs, respectively. In other words, Proposition 1 can be extended to the multi-period case.

To prove that Proposition 1 generalizes, we begin by showing a weaker result: at pure monopoly $\left(m^{\circ}=1\right)$, the dominant firm weakly prefers remaining at pure monopoly and at perfect competition $\left(m^{\circ}=0\right)$, the dominant firm weakly prefers remaining at perfect competition. The pure monopoly case is immediate since pure monopoly maximizes industry profits and at pure monopoly the dominant firm is the recipient of all industry profits for any choice of $m$. To show that at perfect competition, the dominant firm weakly prefers no mergers, we need to show that

$$
v_{f}(m, K) \geq v_{d}(m, K)
$$

which implies that the price of acquiring capital is at least as high as the value of the capital to the dominant firm. To show that the weak inequality (14) holds, consider an initial state $\left(m_{0}^{\circ}, K_{0}\right)$ and the resulting equilibrium path. Along this path, the dominant firm in period $t$ grows at a rate $e_{d, t}$ externally through acquisition of capital, where

$$
e_{d, t}=\frac{m_{t}-m_{t}^{\circ}}{m_{t}^{\circ}}
$$

and at rate $q_{d, t}$ internally through investment. The value to the dominant firm at time $t$ after the merger stage is

$$
v_{d, t}=p_{t} q_{d, t}-c\left(q_{d, t}\right)+\beta(1-\delta) v_{d, t+1}^{\circ},
$$

and the value before the merger stage is

$$
v_{d, t}^{\circ}=e_{d, t} v_{d, t}-\left(e_{d, t}-1\right) p_{K, t} .
$$

A fringe firm behaves competitively and takes the output price sequence $\left\{p_{t}\right\}$ and the capital price sequence $\left\{p_{K, t}\right\}$ as given. A fringe firm could always choose to mimic the dominant 
firm path of external and internal growth and get the same payoff per unit of capital as the dominant firm. Since this path is in the fringe firm's choice set, inequality (14) must hold.

We now turn to the stronger claim in Proposition 1 that at perfect competition, remaining at competition is the unique equilibrium outcome and, analogously, that at pure monopoly, remaining at pure monopoly is the unique equilibrium outcome. To show this, we use the following lemma:

Lemma 3 Consider the finite-horizon version of the model $t \in\{1,2, \ldots T\}, T<\infty$. (i) For all $t, v_{f, t}(m, K)>v_{d, t}(m, K)$, if $m>0$, and $v_{f, t}(m, K)=v_{d, t}(m, K)$ if $m=0$. (ii) For all $t$, $v_{d, t}(1, K)>m v_{d, t}(m, K)+(1-m) v_{f, t}(m, K)$, if $m<1$.

Proof. The proof is in Gowrisankaran and Holmes (2002).

Part (i) of the lemma immediately implies that in the finite-horizon version of the model with $T$ periods, at perfect competition the dominant firm strictly prefers zero mergers, i.e., $F_{t}(0, K)=0$, all $t \leq T$. Analogously, part (ii) implies that $F_{t}(1, K)=1$, all $t \leq T$. Taking limits as $t$ goes to infinity, it must be that $F(0, K)=0$ and $F(1, K)=1$ in the infinite horizon case.

Given that competition and monopoly are absorbing states, it is straightforward to define the competitive and monopoly steady states. As capital is constant in any steady state, investment must exactly offset depreciation, so

$$
q_{\text {com }}^{*}=\frac{1}{1-\delta}
$$

where the asterisk denotes steady state values, and "com" denotes competition. Solving the fringe first-order condition for the stationary equilibrium price, we further obtain:

$$
p_{\text {com }}^{*}=(1-\beta) c^{\prime}\left(q_{\text {com }}^{*}\right)+\beta(1-\delta) c\left(q_{\text {com }}^{*}\right) .
$$

The right side of (16) can be interpreted as dynamic marginal cost. Together, (15) and (16) uniquely define $q_{c o m}^{*}$ and $p_{c o m}^{*}$. Note that the steady state is fully characterized by $q_{c o m}^{*}$ and $p_{c o m}^{*}$, as these variables imply values for other steady state variables, such as $Q_{c o m}^{*}=D\left(p_{c o m}^{*}\right)$ and $K_{c o m}^{*}=(1-\delta) Q_{c o m}^{*}$.

It is straightforward to show that the monopoly stationary price is a markup over the stationary competitive price,

$$
p_{m o n}^{*}=\frac{\varepsilon_{D}}{\varepsilon_{D}-1} p_{c o m}^{*}
$$


where $\varepsilon_{D}$ is the elasticity of demand evaluated at the stationary output level. Together with the analogous condition to (15), (17) defines the monopoly steady state.

\subsection{Dynamics near Competitive Steady State}

The dynamics near the competitive steady state are determined by the slope of the transition function $F$, with respect to changes in $m^{\circ}$, evaluated at perfect competition $m^{\circ}=0$. For notation, we denote this slope as $s$. Our first result concerning this slope is

\section{Lemma 4}

$$
s \equiv \frac{\partial F}{\partial m^{\circ}}(0, K)=\frac{\partial \tilde{m}}{\partial m^{\circ}}(0, K)
$$

Proof. By Proposition 1, we know that $\widetilde{m}(0)=0$ (here we leave $K$ implicit and evaluate the function only at $\left.m^{\circ}\right)$. Part (i) of Lemma 3 implies that $q_{d}(0)=q_{f}(0)$ must hold. The proof of Lemma A1 in Gowrisankaran and Holmes (2002) implies that $q_{d}\left(\widetilde{m}\left(m^{\circ}\right)\right)$ and $q_{f}\left(\widetilde{m}\left(m^{\circ}\right)\right)$ are differentiable at $m^{\circ}=0$. Hence,

$$
\begin{aligned}
\frac{d F}{d m^{\circ}}(0) & =\left.\frac{d}{d m^{\circ}}\left[\frac{\widetilde{m}\left(m^{\circ}\right) q_{d}\left(\widetilde{m}\left(m^{\circ}\right)\right)}{\widetilde{m}\left(m^{\circ}\right) q_{d}\left(\widetilde{m}\left(m^{\circ}\right)\right)+\left(1-\widetilde{m}\left(m^{\circ}\right)\right) q_{f}\left(\widetilde{m}\left(m^{\circ}\right)\right)}\right]\right|_{m^{\circ}=0} \\
& =\frac{q_{d}(0)}{q_{f}(0)} \frac{d \tilde{m}}{d m^{\circ}}(0)=\frac{d \tilde{m}}{d m^{\circ}}(0) .
\end{aligned}
$$

The reason for this result is that when the dominant firm market share is zero, the dominant firm and fringe investment rates are equal, since the dominant firm will forever have market share zero by Proposition 1 . While an increase in share at zero results in a first-order difference between $q_{d}$ and $q_{f}$, this effect is negligible in the limit since these differences are applied to a dominant firm share that is zero in the limit. Thus, next period's concentration $m_{\text {next }}^{\circ}$ will be the same as the post-merger concentration level $\widetilde{m}$, to a first order.

Since the investment effect is second order, the stability of competition depends entirely upon whether the dominant firm is acquiring or selling capital near the limit. If the slope

$\frac{\partial \tilde{m}}{\partial m^{\circ}}$ of the merger function is greater than one, the dominant firm is acquiring capital - a one unit increase in the pre-merger level is associated with a more than one unit increase 
in the post-merger level because of the acquisition. Analogously, if the slope is less than one, the dominant firm is selling off capital near the limit. The following lemma provides a formula for the slope:

Lemma 5 The transition slope $s$ is the unique solution to

$$
s=\frac{4}{3}-\left(\frac{4}{3}-\frac{1}{\psi+1}\right) \beta s^{3}
$$

for $\psi$ defined by

$$
\psi \equiv \frac{1}{2}\left(\lambda+\left[(1-\beta)^{2}+\lambda^{2}+2(1+\beta) \lambda\right]^{\frac{1}{2}}-(1-\beta)\right)>0
$$

and $\lambda$ defined by

$$
\lambda \equiv \frac{-P^{\prime} K}{c^{\prime \prime}}
$$

evaluated at the stationary competitive levels $Q_{\text {com }}^{*}, K_{c o m}^{*}$, and $q^{*}=\frac{1}{1-\delta}$.

Proof. In Gowrisankaran and Holmes (2002), we derive this result by evaluating the slope in a finite horizon game and then taking limits.

Examining (19) for the limiting case of $\beta=0$, it is readily evident that $s=\frac{4}{3}$. Thus, the dynamics near perfect competition for $\beta=0$ do not depend upon demand or cost parameters, and the dominant firm always purchases an additional market share of $e_{d, t}=\frac{1}{3}$. The positive $e_{d, t}$ implies that for $\beta=0$, and by continuity for small $\beta$, perfect competition is unstable. Since $\beta$ enters the $\psi$ term in a complicated way, it is not as obvious what happens for high $\beta$. But we can show that $\lim _{\beta \rightarrow 1} \psi>0$, which from (19) then implies that the transition slope $s$ is strictly less than one for high enough $\beta$. Thus if $\beta$ is sufficiently close to one, there will be sell-offs near the competitive limit. In this case, perfect competition is stable.

To summarize the findings and also present comparative static results for the demand and cost parameters, it is convenient to define the constant elasticity case.

$$
\begin{aligned}
D(p) & =p^{-\varepsilon_{D}} \\
c(q) & =q^{1+\frac{1}{\varepsilon_{S}}} .
\end{aligned}
$$

The parameter $\varepsilon_{D}$ is the elasticity of demand and the parameter $\varepsilon_{S}$ is the elasticity of fringe supply. ${ }^{13}$ Our result is:

13Observe that if the discounted present value of capital to a fringe firm is $v$, then the firm will invest at a rate $q$ that maximizes $v q-c(q)$. It is straightforward to calculate that $\varepsilon_{S}$ is the elasticity of fringe supply with respect to changes in discounted value $v$. 
Proposition 5 (i) For $\beta$ close enough to zero, the transition slope satisfies $s>1$, so competition is unstable. For $\beta$ close enough to $1, s<1$, so competition is stable. (ii) In the constant elasticity case (20), s decreases in $\beta$, assuming that $\varepsilon_{D}=1 .{ }^{14}$ (iii) In the constant elasticity case, $s$ increases in $\varepsilon_{D}$, decreases in $\varepsilon_{S}$, and is constant in $\delta$.

Proof. The proof of (i) is given above. In Gowrisankaran and Holmes (2002), we derive (ii) and (iii) by plugging in the constant elasticity case to the formulae derived in Lemma 5.

We conclude from Proposition 5 that competition tends to be stable, the higher is $\beta$, the lower is $\varepsilon_{D}$, and the higher is $\varepsilon_{S}$. The intuition for these results is summarized in the introduction. To further understand the impact of $\beta$, note that when $\beta=0$, the results of the single-period model apply, and a dominant firm with a positive market share will choose a positive merger. The commitment power available in the $\beta=0$ case is crucial for this result. The dominant firm can credibly choose to operate the capital just as the fringe owner it replaces, before the residual fringe firms make investment decisions. However, with forward-looking behavior, current fringe investment levels depend upon expectations of the dominant firm's future investment and acquisition behavior. The dominant firm would like to commit to its future behavior so as to induce fringe firms to invest little today. But such commitments are not dynamically consistent. By divesting itself of capital, the dominant firm lowers the expectations of future prices, thereby inducing fringe firms to invest less. Thus divestiture becomes a substitute for commitment. ${ }^{15}$

\subsection{Dynamics near Monopoly Steady State}

We now turn to the case of an industry that is close to the monopoly steady state. For simplicity, assume that the constant elasticity structure (20) applies and that $\varepsilon_{D}>1$ so that the limiting case of pure monopoly is well-defined.

Recall that in the analysis of the single-period model, if the share $m^{\circ}$ is close enough to 1 , the dominant firm merges all the way to monopoly, unless the fringe payoff is unbounded

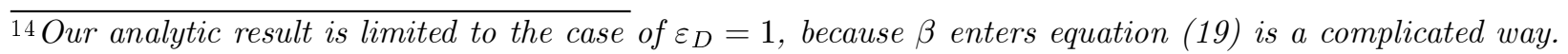
However, it is straightforward to calculate s numerically and verify that the index decreases in $\beta$ for general $\varepsilon_{D}$.

${ }_{15}$ Another means of committing to high output would be for the dominant firm to organize itself into divisions with managers competing against each other. See Kamien and Zang (1990) and Lehto and Tombak (1999). 
at pure monopoly, $v_{f}(1, K)=\infty$. In the single-period case, the fringe value can only be unbounded if demand is inelastic so that the price is unbounded. But in the infinitehorizon case, fringe value can be unbounded even when the price is bounded. To see why, observe that in a monopoly steady state, the dominant firm's output just offsets depreciation, $q_{d}=q^{*}=\frac{1}{1-\delta}$. Since the fringe firm invests at a higher rate, its growth more than offsets depreciation and the firm grows without bound. If $\beta$ is high enough, the growth in future output more than offsets discounting and the fringe value is unbounded. Formally,

Lemma 6 Fix $\varepsilon_{D}>1$ and $\varepsilon_{S}>0$. There exists a cutoff $\bar{\beta}<1$ such that $\beta>\bar{\beta}$ implies $v_{f}(1, K)=\infty$, while $\beta \leq \bar{\beta}$ implies $v_{f}(1, K)<\infty$. The cutoff is the unique $\bar{\beta} \in(0,1)$ satisfying

$$
0 \equiv \varepsilon_{D}\left(1+\frac{1}{\varepsilon_{S}}\right)-\frac{\varepsilon_{D}}{\varepsilon_{S}} \bar{\beta}-\left(\varepsilon_{D}-1\right) \bar{\beta}^{-\frac{1}{\varepsilon_{S}}}
$$

Proof. Straightforward calculations in Gowrisankaran and Holmes (2002) show that when $q_{f}=\frac{1}{\beta(1-\delta)}, p_{m o n}^{*} q_{f}-c\left(q_{f}\right)>0$ if $\beta>\bar{\beta}$; i.e., when the fringe grows at a rate to exactly offset discounting and depreciation and the price is the stationary monopoly level, fringe profit is positive if the discount factor is above the cutoff. It is immediate that fringe value is unbounded. If $\beta \leq \bar{\beta}$, then fringe profit is less than or equal to zero for any $q_{f} \geq \frac{1}{\beta(1-\delta)}$, so fringe value is bounded.

Our result is

Proposition 6 (i) If $\beta \leq \bar{\beta}$ and if the initial state $\left(m_{1}^{\circ}, K_{1}\right)$ is close to $\left(1, K_{m o n}^{*}\right)$, the dominant firm immediately merges to pure monopoly. (ii) If $\beta>\bar{\beta}$, there is never merger to monopoly. Moreover, the pure monopoly outcome is not a stable steady state. (iii) The monopoly stability cutoff $\bar{\beta}$ increases in $\varepsilon_{D}$, decreases in $\varepsilon_{S}$, and is constant in $\delta$.

Proof. To prove (i), consider the graphical proof of Lemma 2. There we showed that with $\beta=0$ the dominant firm would realize a first-order gain from purchasing a small amount of capital, because it could operate the capital at the rate $q_{f}$ without any first-order loss, and would realize a first-order gain from operating the new capital at the rate $q_{d}$ instead of $q_{f}$. When $\beta>0$, the effect of a current transfer on future investment levels by the fringe matter and in general this can lead to a first order loss from a transfer making divestment optimal. However, in the limit where $m^{\circ}$ is close to 1 , the fringe sector is arbitrarily close to zero in size, and this future response of the fringe is a second-order consideration. 
Formally, we use induction on the finite horizon game and assume that $m_{t+1}=1$ if $m_{t+1}^{\circ}$ is sufficiently close to 1 , so that only $q_{f, t}$ and $q_{f, t+1}$ matter. Consider then a small capital purchase by the dominant firm at period $t$, when $m_{t}^{\circ}$ is close to 1 . Following the logic of Lemma 2 , if the dominant firm were to operate this new capital $\varepsilon$ at the rate $q_{f, t}$ it would break even to a first-order, except for the fact that the fringe would raise its investment level in response to the purchase, even without any change in the dominant firm investment level, since it expects $p_{t+1}$ to be higher than it otherwise would. However, because $\beta \leq \bar{\beta}, v_{f}$ is bounded, and the change in $q_{f}$ in response to the purchase is bounded as a function of $\varepsilon$. Since $m_{1}^{\circ}$ is close to 1 , the change in $Q_{f}$ is bounded as a function of $\varepsilon^{2}$, and thus is 0 to a first-order. Thus, by buying a small amount of capital and operating it at the rate $q_{f}$, there is no first-order gain or loss to the dominant firm. Hence, analogous to Lemma 2, to a firstorder, the value to the dominant firm of a small merger is the difference between the value of operating a small amount of its own capital at the rate $q_{f, t}$ and operating it at the rate $q_{d, t}$. This is in turn the difference between the dynamic marginal revenue produced from that unit of capital and the marginal cost of that unit at the two operation levels. Gowrisankaran and Holmes (2002) provide a formal algebraic proof that the merger marginal benefit is the difference between the dynamic marginal revenue and marginal cost at the two operation levels, and show that this difference is positive.

To prove (ii), observe that if $\beta>\bar{\beta}$, then $v_{f}(1, K)=\infty$, so there is never merger to monopoly. Suppose monopoly is stable so that if the industry starts near the monopoly steady state, it gets arbitrarily close to the monopoly steady state for large enough $t$. By definition of stability, for large enough $t$, the price is arbitrarily close to the monopoly steady state level. The arguments in Lemma 6 imply that the fringe value must be infinite. This implies the limiting fringe output more than offsets depreciation so $\lim _{t \rightarrow \infty} q_{f, t}>\frac{1}{1-\delta}=$ $\lim _{t \rightarrow \infty} q_{d, t}$. Since the fringe value is infinite, there are no mergers. But no mergers and the fringe investment rate exceeding the dominant firm's rate implies that the dominant firm's share must be decreasing, a contradiction. This proves (ii).

Claim (iii) follows from straightforward analysis of condition (21) that we perform in Gowrisankaran and Holmes (2002).

Table 1 presents the respective cutoffs $\hat{\beta}$ and $\bar{\beta}$ for stability near perfect competition and 
monopoly for various values of $\varepsilon_{D}$ and $\varepsilon_{S}$. In most of the cases in the table, $\hat{\beta}>\bar{\beta}$. For such cases, when $\beta \in(\bar{\beta}, \hat{\beta})$ neither perfect competition nor pure monopoly are stable and the industry that starts with a positive dominant firm and fringe converges to an intermediate level of concentration. For certain values of $\varepsilon_{D}$ and $\varepsilon_{S}$, we can have $\hat{\beta}<\bar{\beta}$ implying that both perfect competition and pure monopoly are stable.

\subsection{Dynamics Away From Limits}

We analyze the model away from the limits of competition and monopoly by computing the equilibria of the model for the constant elasticity case (20) and different parameter values. There are four parameters for this case, $\varepsilon_{D}, \varepsilon_{S}, \beta$, and $\delta$. We computed equilibria across a variety of parameters but, for space reasons, can only present results for a small but representative set of values. ${ }^{16}$

As in the analytic results of this section, we found that different values of $\delta$ did not substantially affect the results of the model, and hence we focus on the other three parameters, fixing $\delta=0.2$. We present the market share transition function, $F\left(m^{\circ}, K\right)$ for $K=\frac{1}{2}\left(K_{m o n}^{*}+K_{c o m}^{*}\right)$ for a series of different parameter values plotted as a function of $m^{\circ} .17$ Specifically, we examine the impact of changing $\varepsilon_{S}$ (Figure 2), $\varepsilon_{D}$ (Figure 3), and $\beta$ (Figure 4), conditioning on different values for the other parameters, as listed in the figures.

First, note that the figures support the conclusions of our earlier analysis. We find that the same results that hold near the limits of competition and monopoly hold away from the limits. Specifically, elastic demand, inelastic supply, and a high discount factor all reduce the ability of the dominant firm to purchase capital. Moreover, the reason is that these conditions all increase $v_{f}$ relative to $v_{d}$. The result is that the fringe also invests more than the dominant firm under these conditions, so that $F\left(m^{\circ}, K\right)$, which is a combination of the merger and investment effects, also reflects this. We focus on displaying $F\left(m^{\circ}, K\right)$ because the two effects work in the same direction.

In addition to illustrating that the same effects hold away from the limits, the numerical analysis also reveals some other interesting features of the equilibrium. We can see that, for

16The Appendix provides details of the computational algorithm. The programs to compute this model are available on the web at http://www.econ.umn.edu/ gautam.

${ }_{17}$ Again, note that $K$ varies according to $K=\frac{1}{2}\left(K_{\text {mon }}^{*}+K_{c o m}^{*}\right)$ across the different parameter values. 
many of the parameter sets, $F\left(m^{\circ}, K\right)=m^{\circ}$ for intermediate values of $m^{\circ}$, or alternately put, that $F\left(m^{\circ}, K\right)$ crosses the 45 -degree line at these values. This indicates that industries can have steady states with an intermediate level of concentration. ${ }^{18}$ If $F\left(m^{\circ}, K\right)$ approaches the 45-degree line from above (below), the steady state will be stable (unstable) in the sense that an industry that starts with a concentration near the steady state level will converge towards (away from) it. The existence of multiple stable steady states is also consistent with the results near the limits, which find that monopoly and competition can both be stable steady states, and suggests that initial conditions in an industry may determine long-run concentration. Another interesting feature of the computational results is that when $\varepsilon_{S}$ is small, the transition function is lumpy and has a "saw-toothed" pattern. We have found in these cases that the lumpiness comes at the merger stage rather than the output/investment stage.

Lastly, Figure 5 illustrates the capital acquisition function $\tilde{m}\left(m^{\circ}, K\right)$ for the two extreme cases of $\beta=0, \varepsilon_{D}=2, \varepsilon_{S}=0.5$ and $\beta=0.9, \varepsilon_{D}=0.5, \varepsilon_{S}=2$. Consistent with the analytic results, capital acquisition is always higher in the first case than in the second case. Moreover, in the first case, there is always a positive merger, while in the second case, there is a negative merger for $m^{\circ}$ close to zero. However, it is interesting to note that, even in the second case, there is a positive merger for $m^{\circ}$ close to one. The reason for the positive merger is that, even when $\beta>\bar{\beta}$ (as it is in the second case), the logic of Proposition 6 implies that a small merger followed by a decrease in output on the new capital will yield a first-order gain to the dominant firm profits.

\section{The Assumption on Investment and Output}

In formulating the model, we made the assumption that output and new capital are produced in fixed proportions. This greatly simplifies the analysis because a firm has only one choice variable at the output/investment stage. In this section, we show that our results are robust when we relax this assumption.

18To be at a steady state, we need to be at a steady state level of capital in addition to a point where $F\left(m^{\circ}, K\right)=m^{\circ}$. The figures present $F$ for a particular level of $K$ rather than a steady state level. We have found that $F\left(m^{\circ}, K\right)$ varies little with $K$ and, therefore, that the fixed points in the figures are approximately steady levels of concentration. 
A natural generalization of our base model is one where the investment and output decisions are separate and take place in different stages. Suppose that there are three stages: a merger stage, an investment stage, and an output stage. As before, let $K$ denote old capital and $Q$ denote new capital. To allow for the possibility that output may be different from the level of new capital let $Y$ denote output. Since we have assumed throughout that the dominant firm moves first in the merger and investment stages, we assume that the dominant firm moves first in the output stage, as well.

In this new environment we need to specify the output technology in the third stage. A very simple such technology is one where capital is the only input and output can be produced at zero marginal cost up to capacity; i.e., $Y_{t} \leq Q_{t}$. This is different from our base model in that it allows for a firm to costlessly dispose of part of its output instead of bringing it to market. Fringe firms, as price takers, will always produce up to capacity. There are no dynamic considerations from production conditional on $Q_{t}$. Hence, if industry demand is elastic $\left(\varepsilon_{D}>1\right)$, the dominant firm's static residual demand will be elastic and it will produce up to capacity as well. Thus, for the elastic demand case, separating the output choice from the investment choice leads to no change in the equilibrium dynamics.

Suppose, now, that industry demand is inelastic, $\varepsilon_{D}<1$. If, at the output stage, the dominant firm's share of industry capital is small enough, its residual demand will still be elastic and again it will produce up to capacity. But if the dominant firm's share of industry capital is sufficiently high, its residual demand will be inelastic and the dominant firm will produce at less than capacity. This outcome will affect the earlier investment and merger stages. For the single-period version of this model with constant elasticities (20), we can show that if the dominant firm's initial capital share $m^{\circ}$ is sufficiently high, the dominant firm sells capital in the merger stage. Moreover, for $m^{\circ}$ close enough to 1 , the change in the dominant firm's market share during the merger stage (as a percent of the fringe post-merger share) is approximately

$$
\frac{m-m^{\circ}}{1-m}=\left(\varepsilon_{D}-1\right) \frac{\varepsilon_{S}}{\varepsilon_{S}+1},
$$

which is negative since $\varepsilon_{D}<1$. From (22), we can see that our basic results are robust to relaxing the assumption that investment equals output. In particular, net merger activity increases with the elasticity of demand and decreases with the elasticity of supply, just as 
in our base model. Furthermore this case illustrates the effect of introducing dynamics on merger activity. In the original model with the output/investment constraint and a single period, merger activity is always positive. Here, without the constraint, there can be selloffs. The reason for the sell-offs is that there is a commitment problem at the investment stage, since the dominant firm cannot commit to its later behavior at the investment stage. The dominant firm uses sell-offs at the merger stage as a substitute for commitment in the same way that it does when $\beta$ is high.

We can also consider richer models of the output stage in which capital is combined with variable factors to determine output. A natural specification is a Cobb-Douglas technology $Y=Q^{\alpha} L^{1-\alpha}$ where $L$ is the variable input. We examined the implications of this CobbDouglas specification for the constant elasticity demand case (20) and a single period. For this case, equilibrium concentration rises as we increase $\alpha$, the reason being that a higher $\alpha$ implies a greater ability to commit. Moreover, equilibrium concentration increases when $\varepsilon_{D}$ increases and $\varepsilon_{S}$ decreases, exactly as in our base model.

Thus, it appears that our basic results on the impact of elasticities on concentration are not dependent on our simplifying assumption that new capital and output are in fixed proportions. The reason is that the same three key forces will affect the industry in the same ways even for this new model. Moreover, the results show that separating the investment and output processes will simply lessen the ability of the dominant firm to commit to its actions and, in that way, is very similar to increasing the discount factor.

\section{Conclusions}

At the beginning of a typical industrial organization textbook, there is often a discussion of the underlying conditions in an industry that would tend to result in a competitive market structure for the industry in the long run. This list of conditions usually includes an absence of scale economies and an absence of entry barriers. Our results suggest that three additional variables can be added to this list. The competitive outcome is more likely when: (1) firms are more forward-looking, (2) the supply of new capital is more elastic, and (3) demand is less elastic. Moreover, the results show that the initial conditions of the industry can affect the long-run concentration to the point where competitive industries might never become 
monopolized and monopolistic industries might never become competitive.

We have obtained these results using a model that highlights three key forces influencing industry evolution when mergers are allowed: the fact that monopolization allows firms to raise prices, the free-rider effect that limits the ability of firms to merge, and the fact that the dominant firm and the fringe have different incentives to invest in new industry capital. We assume constant returns to scale and increasing adjustment costs for expanding capital, which we view as the "textbook" assumptions of a classic benchmark case. We use the dominant firm model, but there is nothing in the logic of our results that would suggest that these results are specific to models with a single strategic agent.

We have emphasized the "textbook" nature of our model rather than relate our model to specific real world industries. In any real world context, factors that we have left out such as differential efficiencies across firms and scale economies would undoubtedly play a role in the evolution of industry structure. However, we think that the forces that we have emphasized in our model have important real word counterparts. Consider the "textbook" example of monopolization: Standard Oil in the late 19th century. It is well-known that John D. Rockefeller consolidated the petroleum industry by buying out rivals. It is less appreciated that he went to great effort to keep on as employees the owners of the firms that he bought. He recognized that the knowledge of these owners was part of the capital stock of the industry and he did not want this capital to be free to start creating new capital. ${ }^{19}$ This kind of knowledge capital is similar to the concept of capital in our model. Moreover, Rockefeller had to continually buy out new capacity from fringe firms - capacity often built with the express purpose of being bought out. ${ }^{20}$ We think of this as being analogous to the continual buyouts that occur in our model when there is a stationary equilibrium with intermediate concentration. Rockefeller complained that the new capacity meant to be bought out was "blackmail." 21 This illustrates the loss to the dominant firm from not having the ability to make commitments about its future acquisition behavior. Rockefeller tried to keep his acquisitions secret. ${ }^{22}$ One interpretation of this fact is that Rockefeller was 19See Chernow (1998, p. 162).

20See Leeman (1956) for a discussion of the petroleum industry. The situation was similar in the sugar industry (see Zerbe (1969)).

21See Leeman (1956).

22See Chernow (1998, p. 161). 
aware that $p_{K}=v_{f}(m)$ is increasing in $m$, in words, that the price of capital is increasing in the amount of capital that the dominant firm purchases, since it is equal to the fringe value at the resulting state.

There is much talk today that with the "new economy," the issues that were important in the late 19th century have less relevance today. We readily admit that our model has nothing to say about the more recent Microsoft case - the high fixed cost, zero marginal cost, and differentiated product nature of software is not something that our model captures. However, there remain many industries where the technology for producing industry-specific capital is closer to our model than it is to that in the software industry. In industries such as banking, an important part of the industry-specific capital stock is the customer relationship base. Firms in this industry can expand this base by internal investment or external investment.

Thus, the forces that we have highlighted potentially play a role in the evolution of concentration in many industries, along with other forces which we do not allow, such as scale economies and firm efficiency differences. A natural avenue for future research would be to understand the impact of antitrust policies on outcomes and welfare in a model with a richer industry specification. 


\section{References}

1. Carlton, Dennis W. and Jeffrey M. Perloff (1994), M odern Industrial Organization, 2nd ed., New York: HarperCollins.

2. Cheong, K.S. and Ken Judd (1992), "Mergers and Dynamic Oligopoly," mimeo, Hoover Institution, Stanford University.

3. Chernow, Ron (1998), Titan: The Life of J ohn D. Rockefeller, Sr., New York: Random House.

4. d'Aspremont,Claude et al. (1983), "On the Stability of Collusive Price Leadership Canadian J ournal of Economics 16(1), 17-25.

5. Dixit, Avinash (1980), "The Role of Investment in Entry-Deterrence," E conomic J ournal 90, 95-106.

6. Fudenberg, Drew and David Levine (1986), "Limit Games and Limit Equilibria," J ournal of Economic Theory 38, 261-79.

7. Gaskins, Darius W., Jr. (1971), "Dynamic Limit Pricing: Optimal Pricing under Threat of Entry," J ournal of E conomic Theory 3, 306-322.

8. Gilbert, Richard J. and David M. G. Newbery (1982), "Preemptive Patenting and the Persistence of Monopoly," American E conomic Review 72, 514-26.

9. Gowrisankaran, Gautam (1999), "A Dynamic Model of Endogenous Horizontal Mergers," RAND J ournal of E conomics 30, 56-83.

10. Gowrisankaran, Gautam and Thomas J. Holmes (2002), Notes for "Do Mergers Lead to Monopoly in the Long Run? Results from the Dominant Firm Model," available at http://www.nber.org/data-appendix.

11. Harris, Christopher (1986), "Existence and Characterization of Perfect Equilibrium in Games of Complete Information." E conometrica, 53, 613-628.

12. Holmes, Thomas J. (1996), "Can Consumers Benefit from a Policy Limiting the Market Share of a Dominant Firm?" International J ournal of Industrial Organization, Vol. 14, 365-387. 
13. Judd, Kenneth L. and Bruce C. Petersen (1986), "Dynamic Limit Pricing and Internal Finance," J ournal of Economic Theory 39, 368-99.

14. Kamien, Morton I. and Israel Zang (1990), "The Limits of Monopolization through Acquisition," Quarterly J ournal of Economics 105, 465-499.

15. Krishna, Kala (1993), "Auctions with Endogenous Valuations: The Persistence of Monopoly Revisited," American Economic Review 83, 147-60.

16. Kydland, Finn (1979), "A Dynamic Dominant Firm Model of Industry Structure," The Scandinavian J ournal of E conomics 81, 355-366.

17. Leeman, Wayne A. (1956), "The Limitations of Local Price-Cutting as a Barrier to Entry," J ournal of Political Economy 64, 329-34.

18. Lehto, Petri and Mihkel M. Tombak (1999), "Consolidations and the Sequence of Acquisitions to Monopoly," Kellogg Graduate School of Business manuscript.

19. Lewis, Tracy R. (1983), "Preemption, Divestiture, and Forward Contracting in a Market Dominated by a Single Firm," American E conomic Review 73, 1092-1101.

20. Lucas, Robert E., Jr, (1967), "Adjustment Costs and the Theory of Supply," J ournal of Political Economy, 75, 321-334.

21. Maskin, Eric and Jean Tirole (1988), "A Theory of Dynamic Oligopoly I: Overview and Quantity Competition" and "A Theory of Dynamic Oligopoly II: Price Competition, Kinked Demand Curves, and Edgeworth Cycles," E conometrica 56, 549-599.

22. Nocke, Volker N. (2000). "Monopolisation and Industry Structure," Mimeo, Oxford University.

23. Perry, Martin K. and Robert H. Porter (1985), "Oligopoly and the Incentive for Horizontal Merger," American Economic Review 75, 219-227.

24. Prescott, Edward C., and Michael Visscher (1980), "Organization Capital," J ournal of Political E conomy, 88, 446-461.

25. Salant, Stephen W. Sheldon Switzer and Robert J. Reynolds (1983), "Losses from Horizontal Merger: The Effects of an Exogenous Change in Industry Structure on Cournot-Nash Equilibrium," Quarterly J ournal of Economics 98, 185-199. 
26. Shleifer, Andrei and Robert W. Vishny (1986), "Large Shareholders and Corporate Control," Journal of Political Economy 94, 461-88.

27. Spence, A. Michael (1977), "Entry, Capacity, Investment and Oligopolistic Pricing," Bell Journal of Economics 8, 534-44.

28. Stigler, George (1950), "Monopoly and Oligopoly by Merger," American Economic Review Papers and Proceedings 40, 23-34.

29. Stigler, George (1968), The Organization of Industry, Chicago: The University of Chicago Press.

30. Zerbe, Richard, (1969), "The American Sugar Refinery Company, 1887-1914: The Story of Monopoly," Journal of Law and Economics, 12, 339-375. 


\section{Appendix}

\section{Proofs from Main Text}

Lemma $1 A$ dominant firm with $m>0$ has $M R_{d}<p$, and hence $q_{d}<q_{f}$.

Proof. The equilibrium fringe output level $q_{f}\left(q_{d}, m\right)$, given $q_{d}$ and $m$, solves the fringe first-order necessary condition (FONC)

$$
P\left(m K q_{d}+(1-m) K q_{f}\right)-c^{\prime}\left(q_{f}\right)=0
$$

Differentiating yields

$$
P^{\prime}\left[m K+(1-m) K \frac{\partial q_{f}}{\partial q_{d}}\right]-c^{\prime \prime}\left(q_{f}\right) \frac{\partial q_{f}}{\partial q_{d}}=0
$$

Solving for $\frac{\partial q_{f}}{\partial q_{d}}$ yields

$$
\frac{\partial q_{f}}{\partial q_{d}}=\frac{P^{\prime} m K}{-(1-m) K P^{\prime}+c_{f}^{\prime \prime}} .
$$

Now consider the dominant firm's problem,

$$
\max _{q_{d}} P\left(m K q_{d}+(1-m) K q_{f}\right) q_{d}-c\left(q_{d}\right) .
$$

The FONC is

$$
\begin{aligned}
P+P^{\prime}\left[m K+(1-m) K \frac{\partial q_{f}}{\partial q_{d}}\right] q_{d}-c_{d}^{\prime} & =0 \\
P+P^{\prime}\left[m K+(1-m) K \frac{P^{\prime} m K}{-(1-m) K P^{\prime}+c_{f}^{\prime \prime}}\right] q_{d}-c_{d}^{\prime} & =0 \\
M R_{d}-c_{d}^{\prime} & =0
\end{aligned}
$$

for

$$
M R_{d}=P+P^{\prime}\left[\frac{c_{f}^{\prime \prime}}{-(1-m) K P^{\prime}+c_{f}^{\prime \prime}}\right] m K q_{d} .
$$

It is immediate that $M R_{d}<P$.

\section{Lemma 2}

$$
\frac{d\left[m v_{d}(m)\right]}{d m}=v_{d}(m)+m \frac{d v_{d}(m)}{d m}>v_{f}(m), \text { for } m>0 .
$$


Proof. Differentiating the fringe FONC (23) with respect to $m$ yields

$$
P^{\prime}\left[K\left(q_{d}-q_{f}\right)+(1-m) K \frac{\partial q_{f}}{\partial m}\right]=c_{f}^{\prime \prime} \frac{\partial q_{f}}{\partial m},
$$

so

$$
\frac{\partial q_{f}}{\partial m}=\frac{-P^{\prime} K\left(q_{f}-q_{d}\right)}{c_{f}^{\prime \prime}-P^{\prime}(1-m) K} .
$$

The dominant firm value is

$$
v_{d}=\max _{q_{d}} P\left(m K q_{d}+(1-m) K q_{f}\left(q_{d}, m\right)\right) q_{d}-c\left(q_{d}\right) .
$$

By the envelope theorem,

$$
\frac{\partial v_{d}}{\partial m}=P^{\prime}\left[K\left(q_{d}-q_{f}\right)+(1-m) K \frac{\partial q_{f}}{\partial m}\right] q_{d},
$$

so

$$
\begin{aligned}
\frac{\partial v_{d}}{\partial m} & =P^{\prime}\left[-K\left(q_{f}-q_{d}\right)+(1-m) K \frac{-P^{\prime} K\left(q_{f}-q_{d}\right)}{c_{f}^{\prime \prime}-P^{\prime}(1-m) K}\right] q_{d} \\
& =\frac{-P^{\prime} K\left(q_{f}-q_{d}\right) c_{f}^{\prime \prime} q_{d}}{c_{f}^{\prime \prime}-P^{\prime}(1-m) K} .
\end{aligned}
$$

Thus

$$
\begin{aligned}
\frac{d\left[m v_{d}(m)\right]}{d m} & =v_{d}(m)+m \frac{d v_{d}(m)}{d m} \\
& =p q_{d}-c\left(q_{d}\right)+m \frac{-P^{\prime} K\left(q_{f}-q_{d}\right) c_{f}^{\prime \prime} q_{d}}{c_{f}^{\prime \prime}-P^{\prime}(1-m) K} \\
& =v_{f}(m)+p\left(q_{d}-q_{f}\right)-\left(c\left(q_{d}\right)-c\left(q_{f}\right)\right)+m \frac{-P^{\prime} K\left(q_{f}-q_{d}\right) c_{f}^{\prime \prime} q_{d}}{c_{f}^{\prime \prime}-P^{\prime}(1-m) K} \\
& =v_{f}(m)+\left[M R_{d} q_{d}-c\left(q_{d}\right)\right]-\left[M R_{d} q_{f}-c\left(q_{f}\right)\right] \\
& =v_{f}(m)+\int_{q_{d}}^{q_{f}}\left(c^{\prime}(q)-M R_{d}\right) d q,
\end{aligned}
$$

where the integral is strictly positive since $q_{f}>q_{d}$ for $m>0$ and $c^{\prime}(q)>M R_{d}$ for $q>q_{d}$.

\section{Computational Details}

We experimented with a variety of methods for computing the equilibrium of the model and ended up using a finite grid approximation method, as this yielded the best results. For 
this method, we discretized the state space $(K, m)$ into a finite rectangular grid, and then iterated on the fringe and dominant firm policy and value functions (1) - (4) until reaching a fixed point. We generally used a $200 \times 200$ grid for the state space and evaluated all state variables over the ranges $m^{\circ} \in[0,1]$ and $K \in\left[\frac{1}{2} K_{m o n}^{*}, Q_{\text {comp }}^{*}\right]$. For the parameters where $\varepsilon_{D} \leq 1, K_{m o n}^{*}=0$, and so we chose a low positive cutoff instead of 0 to avoid dividing by 0 . For $\beta \geq \bar{\beta}, v_{f}(1, K)=\infty$ (see Lemma 6 ), which makes it hard to compute the fringe value function at the monopoly steady state. Thus, for these parameters, we truncated $m$ slightly below 1, while for the other parameters, we allowed a maximum $m$ of 1 . We specified a minimum $m$ of 0 for all the models.

We experienced convergence problems with the estimation, due to the fact that the finite grid approximation does not have smooth value functions. In order to make the problem smooth, we added a tiny logistic smoothing error to the payoffs at each grid point. We then evaluated values and policy functions assuming that the actual choices of $m$ and $Q_{d}$ were made as though the perceived payoffs were equal to the payoffs as specified by the model plus the smoothing error.

It is easy to see that the larger the grid size, the smaller the smoothing error that is necessary to make the reaction functions smooth up to computer precision. Conceptually, we would like to examine the results of the model as the smoothing error goes to zero and the grid size goes to infinity. We let the size of the smoothing error be $10^{-3}$ times a standard logistic error or smaller, and verified by examining even smaller values that the logistic error had little perceptible impact on the equilibrium at this magnitude.

With the smoothing error, the merger and investment decisions are a weighted sum of the decisions at grid points near the true optimum, where the weights are larger the closer the value at a grid point is to the true optimum. The weights are easy to compute using the standard multinomial logit formulas. We also experimented with using spline approximations of the value functions, which will similarly weight values at grid points to create differentiable approximations. However, we had much better results with the logistic smoothing error. 
Table 1: Critical Values $\hat{\beta}\left(\varepsilon_{D}, \varepsilon_{S}\right)$ and $\bar{\beta}\left(\varepsilon_{D}, \varepsilon_{S}\right)$

\begin{tabular}{|c|c|c|c|}
\hline$\varepsilon_{D}$ & $\varepsilon_{S}$ & $\hat{\beta}$ & $\bar{\beta}$ \\
\hline 2 & .1 & .858 & .852 \\
\hline 2 & 1.0 & .484 & .293 \\
\hline 2 & 3.0 & .352 & .055 \\
\hline 10 & .1 & .946 & .951 \\
\hline 10 & 1.0 & .703 & .684 \\
\hline 10 & 3.0 & .531 & .434 \\
\hline
\end{tabular}

Note: Competition is stable if and only if $\beta \geq \hat{\beta}\left(\varepsilon_{D}, \varepsilon_{S}\right)$ and monopoly is stable if and only if $\beta \leq \bar{\beta}\left(\varepsilon_{D}, \varepsilon_{S}\right)$. 
Figure 1

Profit Maximizing Quantities

for Dominant Firm and Fringe

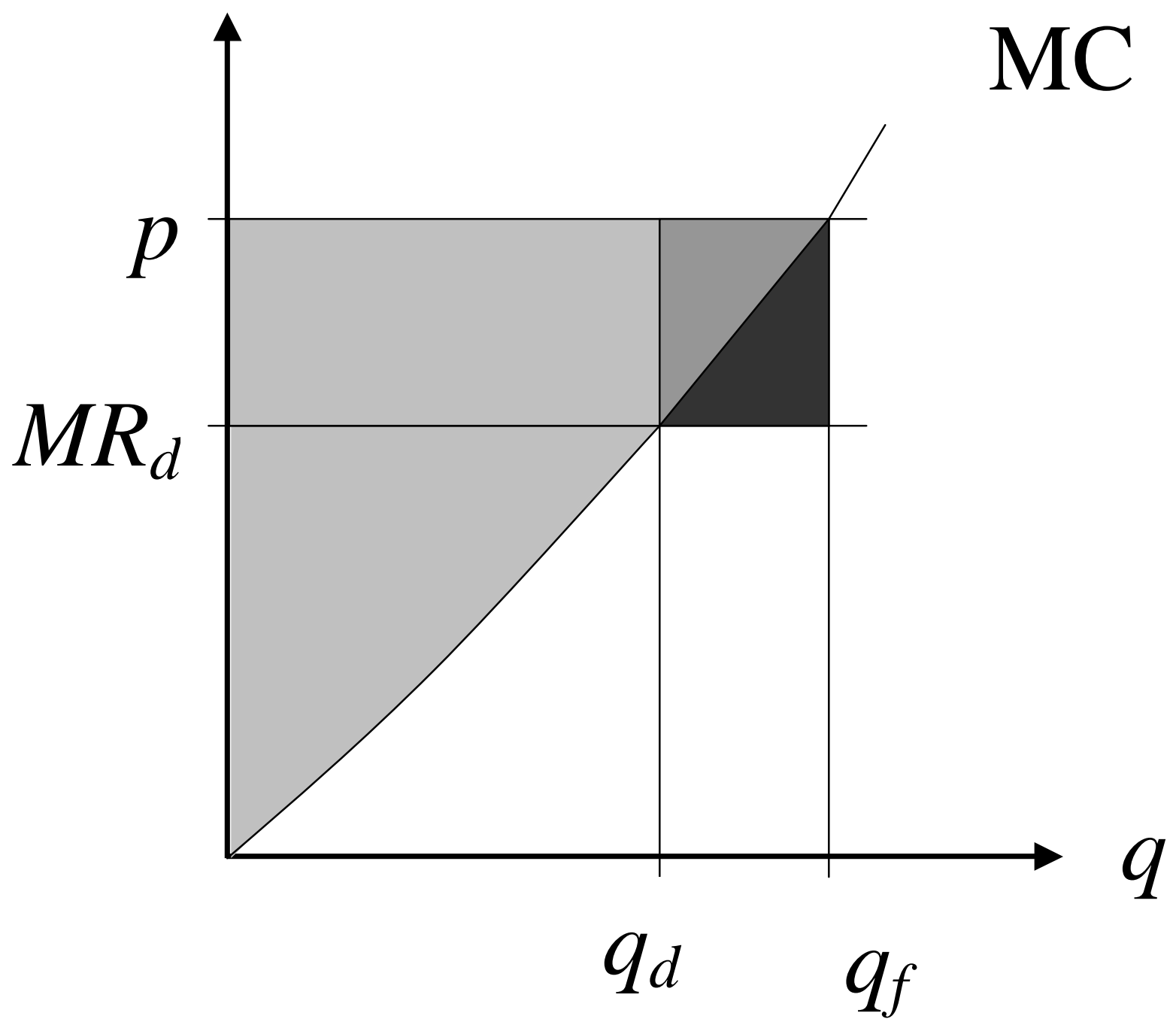


Figure 2a: Effect of $\varepsilon_{S}$ on Industry Transition

$$
\beta=0.9, \varepsilon_{D}=2
$$

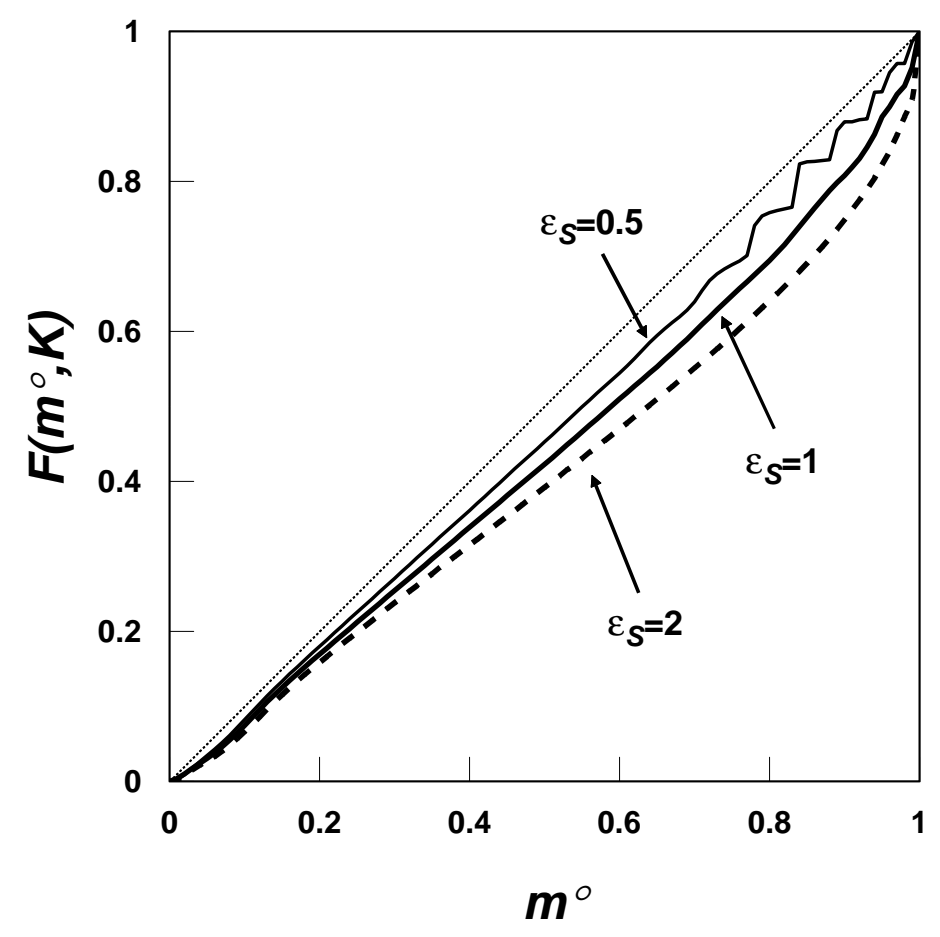

Figure 2b: Effect of $\varepsilon_{S}$ on Industry Transition $\beta=0.9, \varepsilon_{D}=1.1$

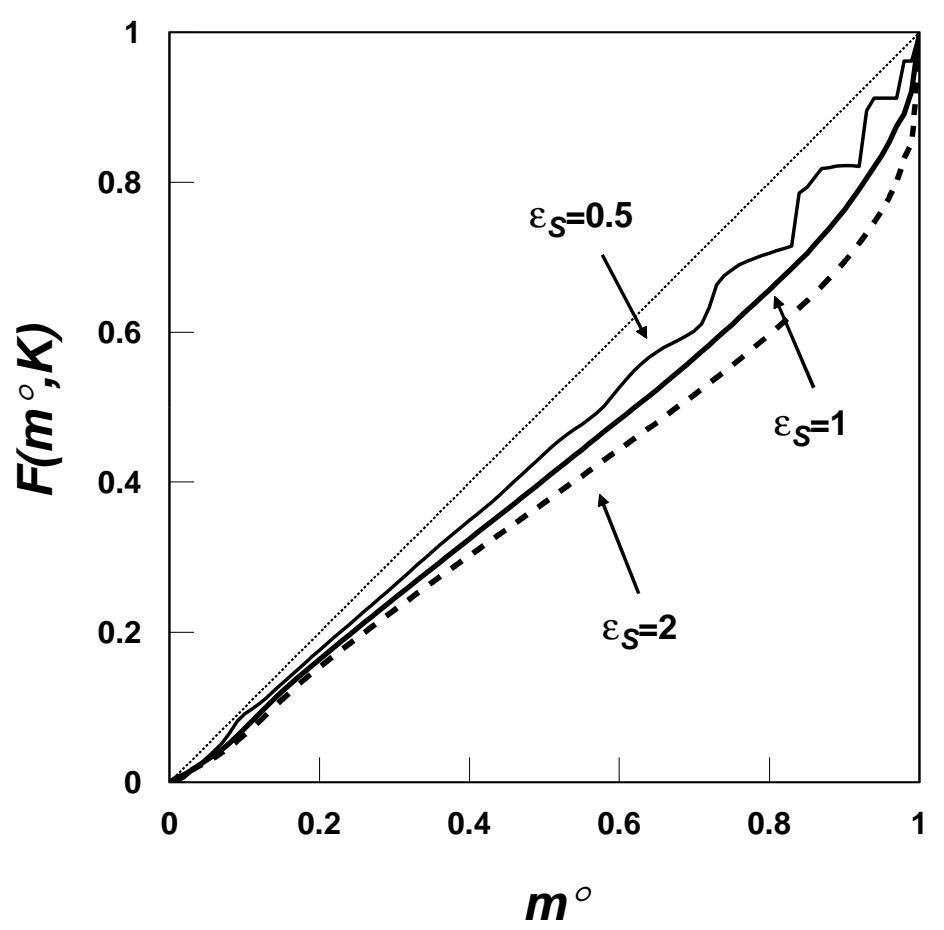


Figure 3a: Effect of $\varepsilon_{D}$ on Industry Transition $\beta=0.3, \varepsilon_{S}=2$

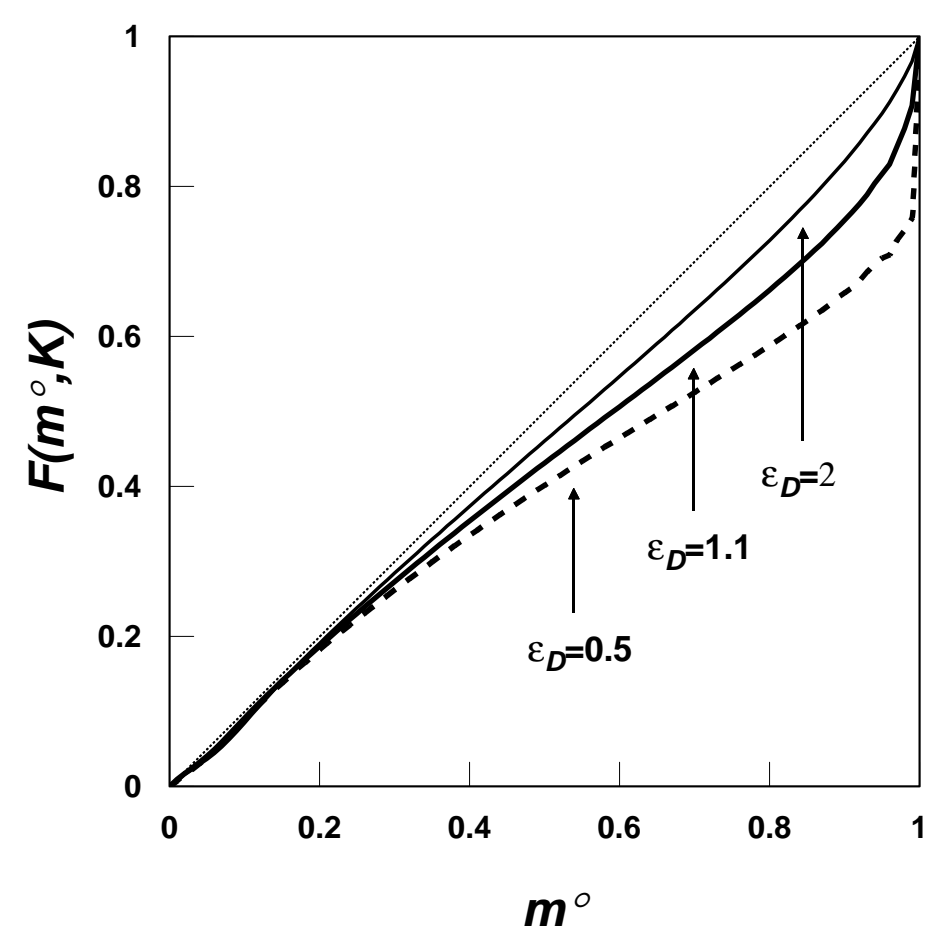

Figure 3b: Effect of $\varepsilon_{D}$ on Industry Transition $\beta=0.3, \varepsilon_{S}=1$

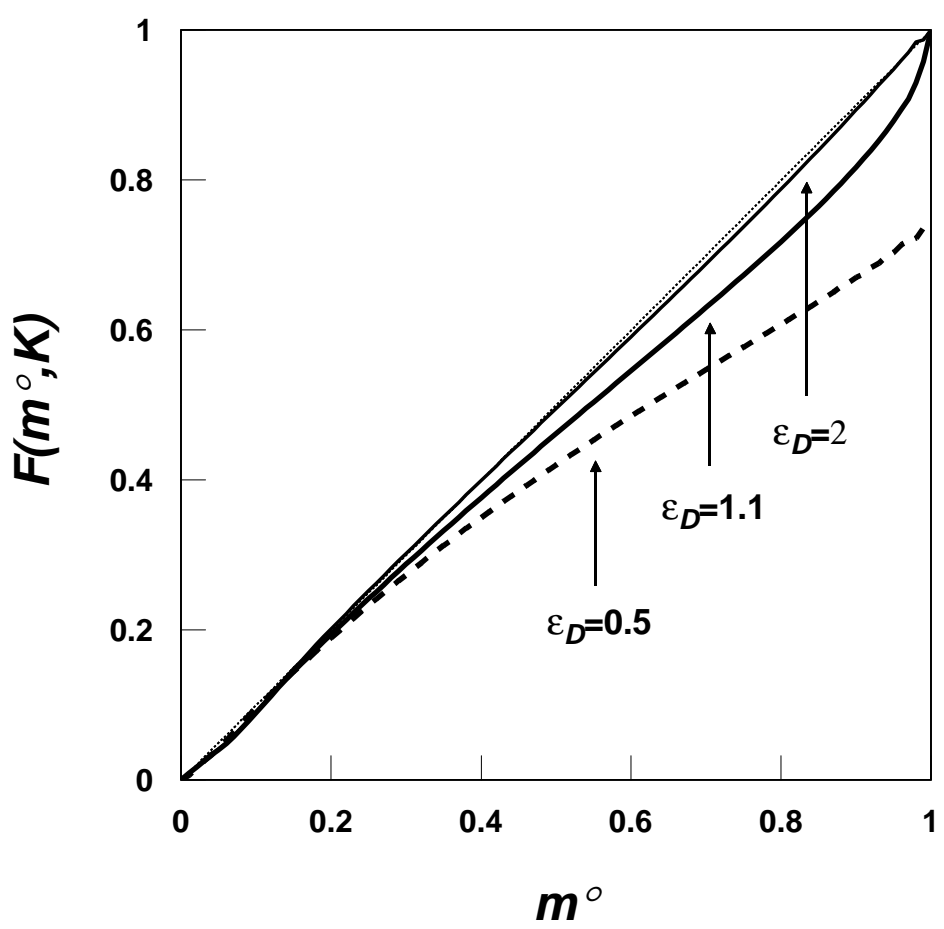


Figure 4a: Effect of $\beta$ on Industry Transition

$$
\varepsilon_{D}=0.5, \varepsilon_{S}=1
$$

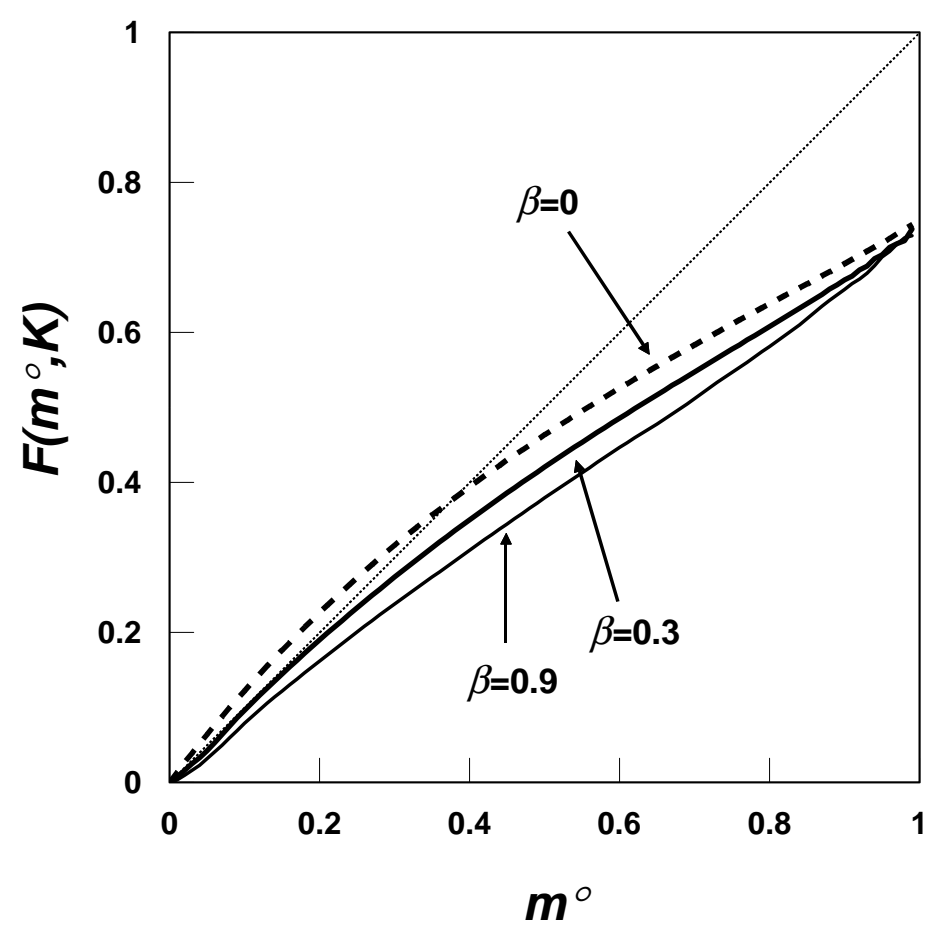

Figure 4b: Effect of $\beta$ on Industry Transition

$$
\varepsilon_{D}=1.1, \varepsilon_{S}=1
$$

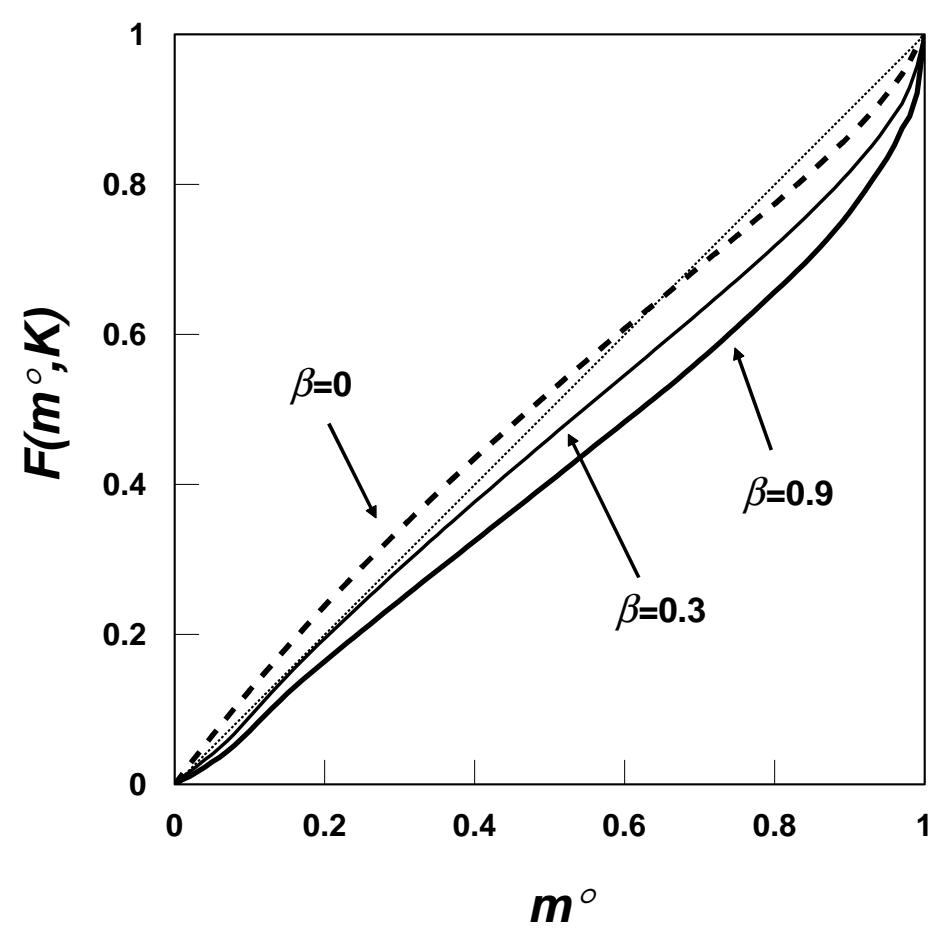


Figure 4c: Effect of $\beta$ on Industry Transition

$$
\varepsilon_{D}=2, \varepsilon_{S}=1
$$

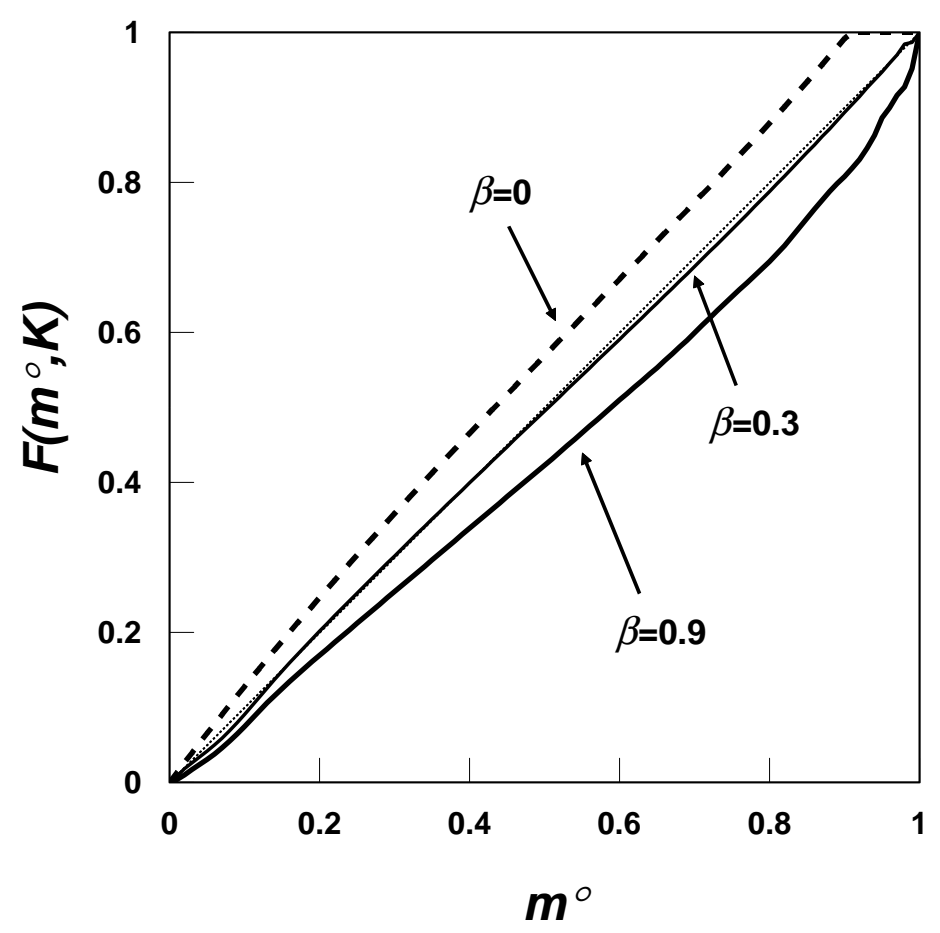

Figure 5: Merger Policy Function for Alternate Parameter Values

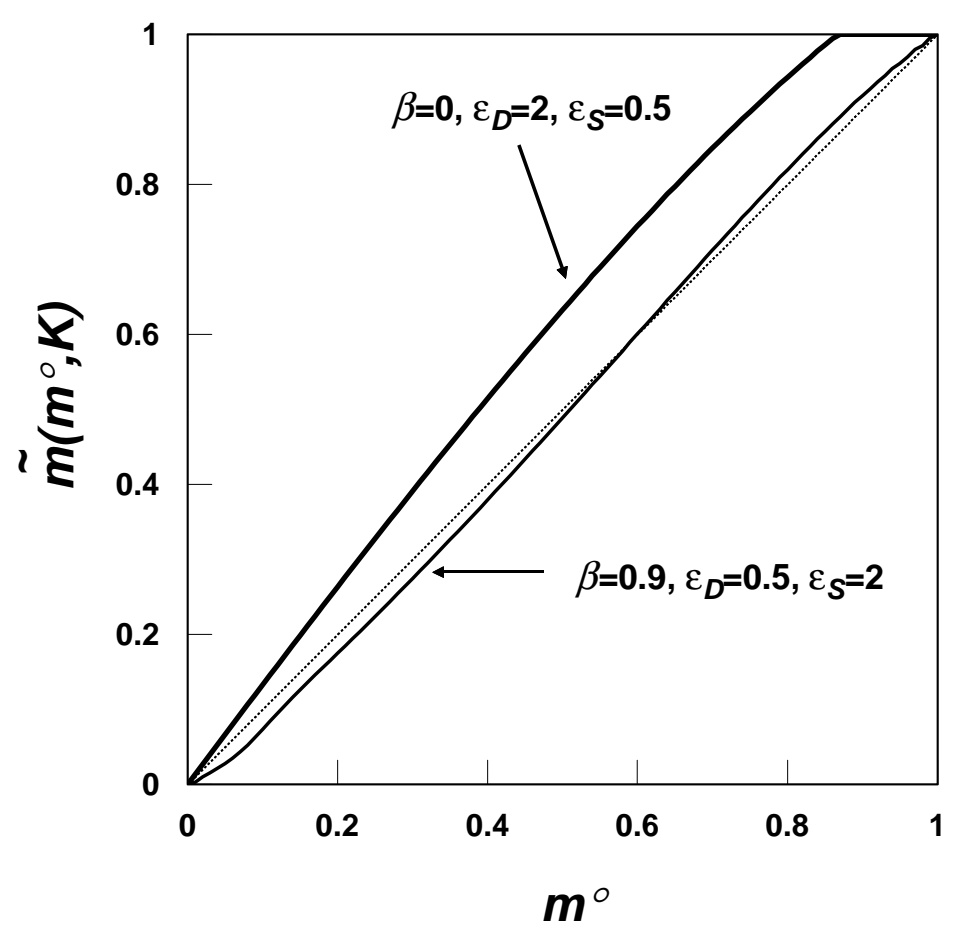

